Article

\title{
The Technology of Copper-Based Red Glass Sectilia from the 2nd Century AD Lucius Verus Villa in Rome
}

\author{
Mario Bandiera ${ }^{1,2, *}$, Marco Verità ${ }^{3}$, Patrice Lehuédé ${ }^{4}$ and Marcia Vilarigues ${ }^{1,2}$ (i) \\ 1 VICARTE, Research Unit Vidro e Ceramica para as Artes, FCT/UNL, Campus Caparica, \\ 2829-516 Caparica, Portugal; mgv@fct.unl.pt \\ 2 Depepartamento de Conservação e Restauro, FCT/UNL, Campus Caparica, 2829-516 Caparica, Portugal \\ 3 LAMA Laboratory, Iuav University, 30125 Venice, Italy; mverita@libero.it \\ 4 C2RMF, Centre de Recherche et de Restauration des Musées de France, Palais du Louvre-Porte des \\ Lions 14, quai François Mitterrand, 75001 Paris, France; patrice.lehuede@culture.gouv.fr \\ * Correspondence: m.bandiera@campus.fct.unl.pt
}

Received: 4 July 2020; Accepted: 27 September 2020; Published: 1 October 2020

\begin{abstract}
This work aimed to investigate the origin of different red hues of Roman copper-based red opaque glass sectilia, to shed light on the production technology behind them. This objective was achieved by the depth study of the samples of glass sectilia, which decorated the villa of co-Emperor Lucius Verus (161-169 AD). These were selected for analysis due to their abundance, the certainty of their date and of their different red and orange hues. Using OM (optical microscopy), colourimetry and FORS (fibre optical reflectance spectroscopy) spectroscopy, four red and four orange hues were individuated. A set of representative samples for each hue was analysed by EPMA (electron probe microanalyses) to detect any correlation between colour and chemical composition. Crystalline phases were investigated through high-resolution FEG-SEM (field emission gun scanning electron microscope), $\mu$ Raman spectroscopy and XRD, for the identification of colouring and opacifying agents and to understand how the different hues are affected by their shape, concentration and dimension. Sub-micrometric particles of metallic copper and cuprite crystals were identified as both the colouring and opacifying agents. These were not present in the same samples and were manufactured by two distinct colouring techniques, corresponding to two different glass chemical compositions. The size and the number of the colouring particles were the main factors that distinguished one hue from another. Although produced through different colouring techniques, some red samples appeared to be very similar to each other. These data enrich a period of the Roman age through some analyses and allow the identification of the type, as well as some of the production conditions of opaque red glass produced during 2nd century $\mathrm{AD}$, which could be considered to be a period of transition from one technology to another.
\end{abstract}

Keywords: copper-based red glass; Roman glass technology; opus sectile; red hues; archaeometry; XRD; FEG-SEM; $\mu$ Raman spectroscopy; EPMA; FORS

\section{Introduction}

\subsection{Brief Overview of the Theory of Opaque Red Glass}

The use of copper to colour glass dates back to the beginning of glassmaking technology. Based on its oxidation state, copper-containing glass has a wide chromatic scale of colours. When copper is dissolved in the melt as a cupric ion $\left(\mathrm{Cu}^{2+}\right)$, a blue turquoise glass is obtained, while the glass is colourless as a cuprous ion $\left(\mathrm{Cu}^{+}\right)$. When the reducing conditions are achieved, and copper separates from the melt in the form of metal micro particles $\left(\mathrm{Cu}^{\circ}\right)$ or as crystals of cuprous oxide $\left(\mathrm{Cu}_{2} \mathrm{O}\right.$, cuprite), 
opaque red glass is generated [1,2]. This process also occurs throughout the formation of some minerals. In the labradorite, for example, the reducing conditions lead to the exsolution of $\mathrm{Cu}^{\circ}$ nanoparticles from the host feldspar during the cooling phase, producing red transparent layers [3,4].

Despite the considerable number of studies on the mechanism of colour in opaque red glass, the nature of the colouring agents is not accepted unanimously. Several studies, both in the field of archaeological and material engineering proved the presence of two main copper-rich phases-dendritic crystals of cuprite and metallic copper particles, which were detected both in glass and glaze [5-10].

The formation of these particles in the glass requires reducing conditions during the process (melting and cooling phases), in order to decrease the partial pressure of oxygen [2,11]. Due to the low solubility of metallic copper, this element is usually introduced as copper oxide, which dissolves in the ionic form $\left(\mathrm{Cu}^{2+}, \mathrm{Cu}^{+}\right)$. In order to create the correct redox conditions inside the molten glass, elements with the proper oxidation state (iron: $\mathrm{Fe}^{2+}$; tin: $\mathrm{Sn}^{2+}$; antimony: $\mathrm{Sb}^{3+}$ ) are added to the melt, acting as reducing agent. It is generally accepted that the redox reactions between the copper and the reducing agents occur mainly when the glass is sufficiently viscous and starts to cool, at a temperature below its melting point [11]. Moreover, the chemical composition of the glass determines the formation of one of these crystalline phases. In glass with high copper ( $\mathrm{CuO} 5-10 \mathrm{wt} . \%)$ and lead (PbO 15-50 wt.\%) contents, the formation of cuprite crystals is favoured. Instead, in the case of a lower concentration of copper $(\mathrm{CuO}<5 \mathrm{wt} . \%)$ and a significant amount of iron $\left(\mathrm{Fe}_{2} \mathrm{O}_{3} 2-5 \mathrm{wt} . \%\right)$, sub-micrometric metallic copper particles precipitate [12-16]. The rate of cooling can modify the nucleation or the growth of the crystalline phases, which are controlled through specific heat treatment, promoting different hues of opaque red glass [17].

Orange glass could be considered as copper-red glass, obtained by combining high concentration of copper and lead with delicate heat treatment, to favour the nucleation of small cuprite crystals $(<400 \mathrm{~nm})[17]$.

\subsection{Brief History of Opaque Red Glass Production}

A substantial number of analyses of archaeological opaque red glass established the existence, along the centuries (since the 2nd millennium BC until nowadays) of two types of opaque red, coloured by metallic copper or cuprite. The oldest samples from Egypt (1500-1400 BC) showed a high concentration of copper ( $\mathrm{CuO} 5-9 \mathrm{wt} . \%)$ and sporadically considerable contents of antimony and iron [18]. The colour was dark red or "liverish" (red brown), and both metallic copper or cuprite were detected $[18,19]$.

During the second half of the 1st millennium BC (4th-1st century BC), the archaeometric analyses highlighted a drastic change in the opaque red glass production. In samples from Nimrud (4th/3rd century BC Mesopotamia), high lead ( $\mathrm{PbO} 15-30 \mathrm{wt} . \%$ ) and copper (CuO 5-10 wt.\%) contents were detected, together with a high amount of antimony oxide $\left(\mathrm{Sb}_{2} \mathrm{O}_{3} 1-4.8 \mathrm{wt} . \%\right)[6,18]$. Micrometric cuprite crystals $\left(\mathrm{Cu}_{2} \mathrm{O}\right)$ in the dendritic shape were identified as responsible for its colour. The formation of cuprite crystals is considered to be the result of a well-mastered technology that probably requires specifically long heat treatment, to allow the growth of the crystals [6,17-19]. This type of bright opaque red, called "sealing wax", was highly sought after and produced in ancient Egypt and Ptolemaic Egypt, the Mesopotamian region (Nimrud) and probably along the Syro-Palestinian coastal [20,21]. It was abundantly found in the North Europe, where it was probably not produced but imported from Egypt [22], and among the La Tene cultures. It was employed as enamel to decorate metalworks, to substitute precious stones in jewellery, as rods in glass mosaic vessels and in the production of rare bowls [13,23-28].

A modification in the manufacturing technology of opaque red glass occurred when the Roman Empire established its domain in the entire Mediterranean basin (around the 1st century AD). This third type was characterized by a gradual decrease of copper ( $\mathrm{CuO} 1-5 \mathrm{wt} . \%)$ and lead ( $\mathrm{PbO}<15 \mathrm{wt} . \%)$ contents in the glass and the addition of iron $\left(\mathrm{Fe}_{2} \mathrm{O}_{3} 1-4 \mathrm{wt} . \%\right)$. Although this new opaque red glass, called red brown, is indicated as being duller than sealing wax, several red hues are included under this 
designation. It was recently verified that no marked visual differences were observed among Roman red brown and sealing wax [29]. Furthermore, it was established that sub-micrometric particles of metallic copper, varying between 60 and $400 \mathrm{~nm}$, generate colour and opacity in the red brown glass [12,30]. However, the presence of cuprite crystals was identified in some Roman red brown samples, keeping the debate about the true nature of the colouring agent still alive [19]. The precipitation of these metallic particles occurs during the cooling phase, through the redox reactions between copper and the reducing agents. The formation of colour does not need heat treatment, cutting down on the time of production [2].

After the 1st century AD and the massive scale glassmaking production, red brown became the dominant type of red glass during the Roman age. Since fewer metals and less time were required to produce red brown, it probably represented an economic advantage for the increased demands of coloured glass for the manufacture of mosaic tesserae, rods, sectilia and beads [23,24]. This type of opaque red continued to be produced abundantly throughout the centuries, with minor changes in the chemical composition, until the present day [31].

\subsection{Roman Opaque Red Glass}

The considerable number of studies on analyses of Roman opaque red glass, highlighted the presence of some anomalous chemical composition for the Roman age, generating many questions that are still unsolved regarding the technology of its production.

It was established that the Roman glass was made by combining sand, which contains silica and carbonaceous minerals or shells, and a mineral that is extremely rich in sodium carbonate like a fluxing agent, called natron. The resulting chemical composition of the Roman glass is poor in $\mathrm{K}_{2} \mathrm{O}$, $\mathrm{MgO}$, which are usually lower than $1.5 \mathrm{wt} . \%$, and have low contents of $\mathrm{P}_{2} \mathrm{O}_{5}$ (usually $<0.2 \mathrm{wt} . \%$ ) [32]. Furthermore, at the beginning of the Roman glass studies, it was already observed that Roman glass discovered in different parts of the Roman Empire showed similar chemical composition [32]. In the last twenty years, it was established that the Roman glassmaking industry was organized in two steps: (a) large furnaces, located in the Levant region or in Egypt produced massive amount of raw glass, which (b) was broken into several chunks and shipped to the secondary furnaces or workshops spread-out in the different regions of the Empire [33]. In the secondary furnaces, the raw glass was re-melted to be coloured or to be used in the manufacturing of glass object [33]. This model explains the similar and almost constant chemical composition of the Roman glass. Furthermore, this model was confirmed by the archaeological excavation in Egypt and in Israel, in which large furnaces were uncovered and identified as the primary furnaces [33]. In contrast, no archaeological evidences of the secondary furnaces were found, and it did not allow us to have a clear understanding of the production of coloured glass.

The higher contents of $\mathrm{K}_{2} \mathrm{O}, \mathrm{MgO}$ (both $>1.5$ wt.\%) and $\mathrm{P}_{2} \mathrm{O}_{5}$ (>0.5 wt.\%) often detected in Roman opaque red glass, compared to other colours, created a controversial issue [34,35]. Some authors attributed the presence of these anomalous values to the addition of fuel ash from the furnace [36-40], while other support the hypothesis that another fluxing agent, different from the traditional natron [32, 33], could be used for technological benefit in specialised production centres [35,41,42].

A question concerns the production of other types of opaque red glass, for example, sealing wax. What happened after the invention of the red brown technology since the Roman Empire, is still not clear $[43,44]$.

Furthermore, establishing a historical development of the colouring technique of Roman opaque red glass is very complex. Most of the analyses are focused on mosaic glass tesserae, which mainly concerns the Late Antiquity, while a small number of analyses were performed on other artefacts made by opaque red glass. Moreover, although, mosaic glass decorations are usually well-dated, it could be possible that the glass mosaic tesserae were re-used from previous sites or might be substituted in some restoration and could give (in some cases) misleading interpretation. Finally, a complete 
understanding of the production technology, or the recipe, is precluded by the lack of archaeological evidences (furnaces, scraps, tools, etc.) of Roman written technical sources.

Due to the shortage of chemical analyses that investigated orange glass, it was still not possible to establish how this colour was manufactured. There are few analyses on the orange glass before the Roman age, while a considerable amount of chemical analyses covers the period from the 1st century AD to 6th century AD of the Roman Empire [15,39,40,45-47]. This suggests that an increase of its use occurred with the spread of the mosaic or opus sectile decorative technique in many regions of the Roman Empire, in which a more extended chromatic scale was necessary.

\subsection{The Sectilia from the Gorga Collection}

Opus sectile (cut work) was a decorative technique where the panels were composed on a resin and plaster support, by inlaying flat pieces of coloured marbles and glass; afterwards these were applied on pavements or walls $[48,49]$.

The most significant evidence of glass sectilia is found in the collection of the Italian tenor Evangelista Gorga (1865-1956). This collection includes 26,000 coloured glass sectilia, showing different colours and patterns, attributed to the decoration of the co-Emperor Lucius Verus villa (161-169 AD), located on via Cassia ( $8 \mathrm{~km}$ from Rome) $[50,51]$. The attribution was confirmed by recent excavations in the area of the Lucius Verus villa [51,52], uncovering more than 800 glass sectilia, later studied by the archaeologists and glass technicians, and resulting in a collection identical to that of the Gorga collection. However, it could not be excluded that some sectilia show a different provenance. The works of Saguì [50], Verità [53] and Tesser [54] established the ability of glassmakers to create patterns similar to natural stone, in order to imitate precious marbles that are commonly used in private Roman architecture.

Glass sectilia were manufactured through different techniques. Some of these were made from cane slices (Figure 1b,c) juxtaposed on a plane and fused in a kiln or furnace. Afterwards, these were pressed on the side and from the top, to adhere and form slabs [50]. Other thinner sectilia were cut from the cast, pressed and drawn at the corners (Figure 1a) [50]. Finally, the samples used as a frame in the decoration were obtained by casting the molten glass into a mould (Figure 1d) [50].

(a)
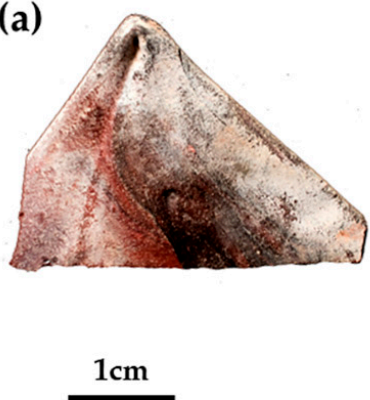

(b)

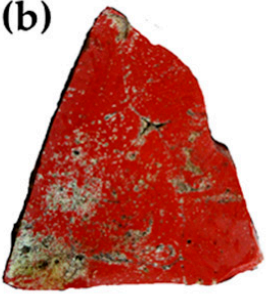

(c)

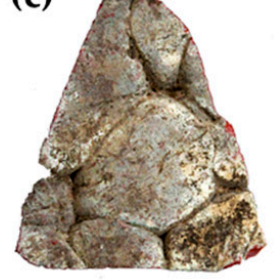

(d)

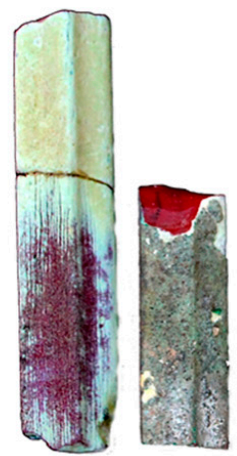

Figure 1. Technique used to manufacture the sectilia-thin sheets stretched at the corner with visible tools markers (a); thick sample with flat surface (b) and composed by an ensemble of several canes (c), and visible on the back of; cast in a mould technique (d). The white and green layers on the surface is due to the weathering of the glass.

In this frame, the Gorga collection turned out to be of fundamental interest for the archaeometric studies of opaque red glass for several reasons. (1) The certain date of the sectilia, (2) the scant number of analyses concerning the 2 nd century AD red glass, (3) could be a result of a century of transition from the sealing wax to the production red brown and (4) the abundance of red sectilia and the presence of different red hues. All these aspects make this collection a unique opportunity to examine the technological aspect behind Roman red glass production. 
This work aimed to characterize the different red glass hues identified in the Gorga collection through a multi analytical approach. A part of the samples was already analysed and previously reported [29]. Nevertheless, the present work increased the number of analysed samples for each red hue and four orange samples were included. Furthermore, a new set of 38 opaque red sectilia was selected and analysed by colourimetric measurements, optical microscope and reflectance spectroscopy, to confirm and establish the red hues identified by naked eye observations. In the previous publication [29], the colouring agent in each red hue was not identified with certainty. In this investigation, the crystalline phases that affect each hue, were identified through new measurements by means of FEG-SEM, Raman spectroscopy and X-Ray diffraction, allowing to clarify the nature of the colouring agent. The analytical results permit us to understand and to establish the factors, such as chemical composition or the nature and dimensions of particles that contribute to generate each red hue. The results obtained shed new light on the probable recipes connected with the production of copper-based opaque red glass, during the 2nd century AD.

\section{Materials and Methods}

The colour and the thickness of the sectilia were used as a parameter to select the samples for analyses. Through naked-eye observation, different hues from orange, red, to dark brown were identified, and for each hue, several samples were collected. Furthermore, in order to investigate possible differences and correlations between chemical composition, microstructure, and colour, the samples were manufactured with a different technique, and consequently, different thickness were selected to be analysed (Figure 1).

\section{Analytical Technique}

The selected samples were studied by colourimetric measurements (except samples AR2, R2, R5, R6, R11 and R14, due to their small size) and fibre optical reflectance spectroscopy (FORS) [29]. MAYA 200 PRO from Ocean Optics spectrophotometer with a single beam dispersive optical fibre was used together with a 2048 CCD Si detector that allows operating in the 200-1050 nm range. The light source was an HL-200-HP $20 \mathrm{~W}$ halogen from Ocean Optics, with a single optical path between 360 and $2500 \mathrm{~nm}$. The spectra were taken on the glass surface, in reflectance (R) mode, with a $45^{\circ} / 45^{\circ}$ configuration (illumination angle/acquisition) and ca. $2 \mathrm{~mm}$ diameter of the area analysed. Spectra were obtained between 380 and $1050 \mathrm{~nm}$, with an integration time of $8 \mathrm{~ms}$ per scan and 15 scans. A Spectralon ${ }^{\circledR}$ surface was used as a reference for calibration.

Through the reflectance spectra, it is possible to calculate the band gap energies of semiconductor materials, using the following equation [55-58]:

$$
(\alpha h v)^{n}=A(h v-E g)
$$

where $\alpha$ is the absorption coefficient, $h v$ is the energy of the incident photon, and $E g$ is the band gap energy, $A$ is a proportionality constant and $n$ is an exponent related to the optical transition. As mentioned by Rosi [55], it was necessary to convert the FORS spectra into Kubelka-Munk, values which were proportional to the absorption coefficient. Afterwards, a band gap energy was calculated by extrapolating the linear region of a plot of $(\alpha h v)^{2} v s h v$ [55-58].

Optical microscopy observations were conducted with a Zeiss Axioplan 2 Imaging system (HAL 100) coupled to a Nikon DXM1200F digital camera (Nikon, Tokyo, Japan) and ACT-1 software (Act 1 Systems, Los Angeles, CA, USA), with different illumination modes (bright field and dark field) [29].

After the identification of the red and orange hues, a set of 25 samples was selected for a deep chemical and mineralogical characterization (see Table 1). These samples were embedded in resin and prepared in polished section, coated by carbon or platinum for EPMA and FEG-SEM analyses. 
Table 1. Samples investigated by UV-VIS spectroscopic measurements and chemical and mineralogical analyses.

\begin{tabular}{|c|c|c|c|c|c|c|c|}
\hline Group & Samples & O.M. & FORS & FEG-SEM & EMPA & Raman & XRD \\
\hline Gr-1 & $\begin{array}{l}\text { R2-R3-R4-R5-R6-R7- } \\
\text { R8-R14-R15-R16; } \\
\text { R25-R26-R27-R28- } \\
\text { R29-R30-R31-R32- } \\
\text { R33-R34 }\end{array}$ & $\begin{array}{c}\text { R2-R3-R4-R5-R6- } \\
\text { R7-R8-R14-R15-R16; } \\
\text { R25-R26-R27- } \\
\text { R28-R29-R30-R31- } \\
\text { R32-R33-R34 }\end{array}$ & $\begin{array}{c}\text { R2-R3-R4-R5-R6 } \\
\text {-R7-R8-R14-R15-R16; } \\
\text { R25-R26-R27 } \\
\text {-R28-R29-R30-R31 } \\
\text {-R32-R33-R34 }\end{array}$ & $\begin{array}{c}\text { R2-R3-R4- } \\
\text { R5-R6-R7- } \\
\text { R8-R14-R16- } \\
\text { R26-R27-R31-R33 }\end{array}$ & $\begin{array}{l}\text { R2-R3-R4- } \\
\text { R5-R6-R7-R8 }\end{array}$ & $\begin{array}{c}\text { R2-R3-R4-R5- } \\
\text { R6-R7-R8-R25- } \\
\text { R26-R27-R28- } \\
\text { R29-R30-R31-R34 }\end{array}$ & $\begin{array}{c}\text { R2-R4- } \\
\text { R5 }\end{array}$ \\
\hline Gr-2 & $\begin{array}{l}\text { R10-R17-R18- } \\
\text { R19-R20-R21 }\end{array}$ & $\begin{array}{l}\text { R10-R17-R18-R19- } \\
\text { R20-R21 }\end{array}$ & $\begin{array}{l}\text { R10-R17-R18- } \\
\text { R19-R20-R21 }\end{array}$ & R10-R17-R19 & R10 & $\begin{array}{l}\text { R10-R17-R18- } \\
\text { R19-R20 R21 }\end{array}$ & R10 \\
\hline Gr-4 & R9-R11-R12-R13 & R9-R11-R12-R13 & R9-R11-R12-R13 & R9-R11-R12 & R9 & R9-R11-R12-R13 & 1 \\
\hline Gr-5 & $\begin{array}{l}\text { AR1-AR2- AR4- } \\
\text { AR6-AR7-AR-8 }\end{array}$ & $\begin{array}{c}\text { AR1-AR2- } \\
\text { AR4-AR6-AR7-AR-8 }\end{array}$ & $\begin{array}{l}\text { AR1-AR2-AR4- } \\
\text { AR6-AR7-AR-8 }\end{array}$ & $\begin{array}{l}\text { AR1-AR2- } \\
\text { AR4-AR8 }\end{array}$ & $\begin{array}{l}\text { AR1-AR2- } \\
\text { AR4 }\end{array}$ & $\begin{array}{l}\text { AR1-AR2-AR4- } \\
\text { AR6-AR7-AR-8 }\end{array}$ & $\begin{array}{l}\text { AR1-AR2 } \\
\text { AR4 }\end{array}$ \\
\hline
\end{tabular}

Chemical quantitative analyses were carried out with a Cameca SX-50 at the Stazione Sperimentale del Vetro, Murano, Murano-Venice (Italy), equipped with three wavelength-dispersive spectrometers (PET, LiF and TAP crystals). The operating conditions were-accelerating potential $15 \mathrm{kV}$, beam current $20 \mathrm{nA}$ for major and minor components or $100 \mathrm{nA}$ for trace elements, respectively. A $40 \times 50 \mathrm{~mm}$ scanning electron beam and limited counting time (10 s for major and minor elements, 20-30 s for trace elements) were employed to ensure that no significant alkali drift (ion migration) occurred during the irradiation [59].

The micro-texture was investigated through a field emission gun scanning electron microscope (FEG-SEM, JEOL 7800F, JEOL, Tokyo, Japan), which was used after platinum coating. At the same time as SEM observations, EDS (energy dispersive x-ray spetroscopy) analysis was carried out on the samples, using a BRUKER Quantax 400 system (BRUKER, Billerica, MA, USA). The intensity of the electron beam current was $1 \mathrm{nA}$. During the analysis it was scanned on a surface area larger than $2 \mu \mathrm{m}$, to prevent alkali drift.

The identification of the crystalline phases was conducted by $\mu$ Raman spectroscopy, a Labram 300 Jobin Yvon spectrometer (HORIBA, Kyoto, Japan) equipped with a solid-state $50 \mathrm{~mW}$ laser, operating at $532 \mathrm{~nm}$. The spectra were recorded as an extended scan and the system was calibrated using a silicon standard. The laser beam was focused either with a $50 \times$ or a $100 \times$ Olympus objective lens and its power at the surface of the samples was controlled with neutral density filters (optical densities 0.3 and 0.6). Raman data analysis was performed using LabSpec 5 software (HORIBA, Kyoto, Japan) and all spectra are presented as acquired, without any baseline correction or other treatment [29]. The RRUFF database was useful for the identification of some crystalline phases.

X-ray diffraction was used in some samples where Raman spectroscopy did not allow the identification of the colouring agent, and in the orange samples, to understand whether other opacifying agents were used. The measurements were performed by X'Pert PRO MPD (PANalytical B.V., Almelo, Netherlands), equipped with an X-ray tube with $\mathrm{Cu}$ anode (1.54059 A, K $\alpha, 45 \mathrm{kV}, 40 \mathrm{~mA}$ ) and an $X^{\prime}$ Celerator detector (ultra-set X-ray 1D detector based on Real Time Multi Steps-RTMS-technology). The scans were collected in the angular range of $3^{\circ}-89^{\circ} 2 \theta$ with a $0.03^{\circ}$ virtual step size and $30 \mathrm{sec} / \mathrm{step}$ counting time. The XRD data were processed by the X'Pert HighScore (PANalytical B.V., Almelo, Netherlands). In order to avoid any contamination of resin peaks, the analyses were performed on bulk samples.

\section{Results}

\subsection{Identification of the Red Hues}

\subsubsection{The Sampling}

Through naked-eye observation, five primary hues were identified (Figure 2). The first hue, indicated as Gr-1, included both thin and thick sectilia, of brick red and duller red colour (Figure 2a). 
The second red hue was composed of reddish-brown glass samples (Gr-2), showing a homogeneous texture, and in some of them a sparkling effect was observed (Figure 2b). In the third hue, the samples were characterized by an extremely heterogeneous morphology, constituted by red and black stripes, making these types of glass dark-red in colour (Gr-3) (Figure 2c). The fourth hue included four samples (R9-R11-R12-R13) presenting a sort of gem effect, seeming very homogeneous and shiny, they represented another red hue called Gr-4 (Figure 2d). The fifth hue (Figure 2e) was made up of orange samples (Gr-5), in shades ranging from reddish orange to yellowish orange.

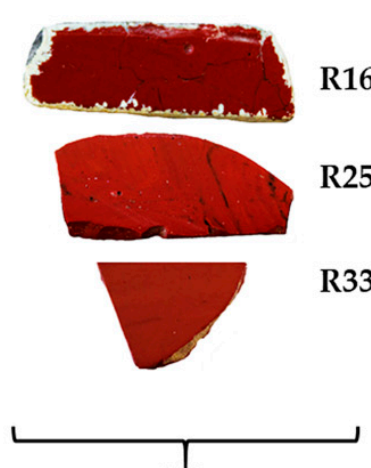

(a)

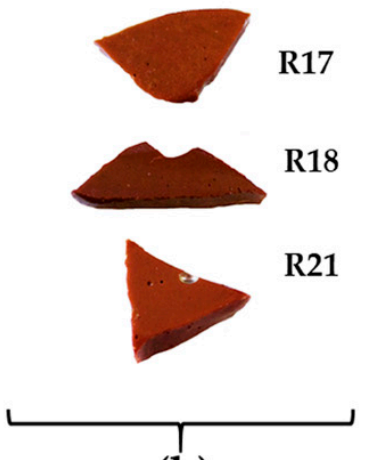

(b)

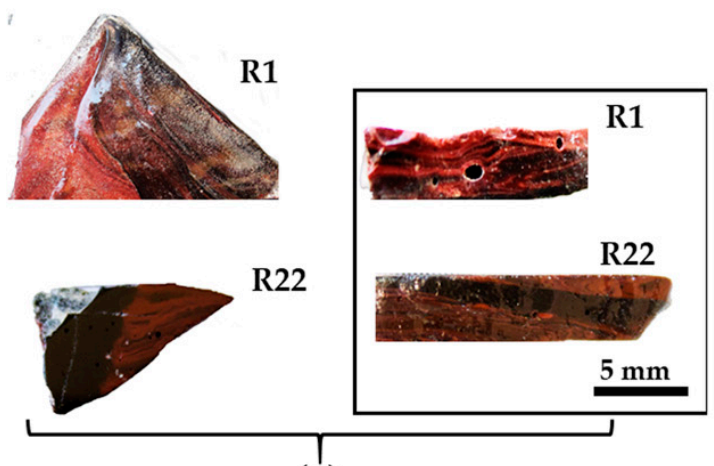

(c)

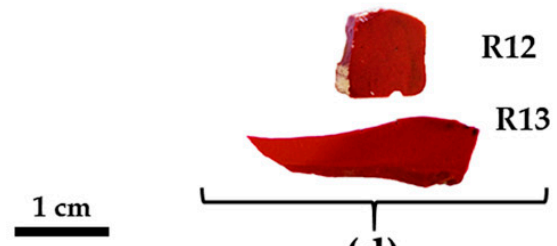

(d)

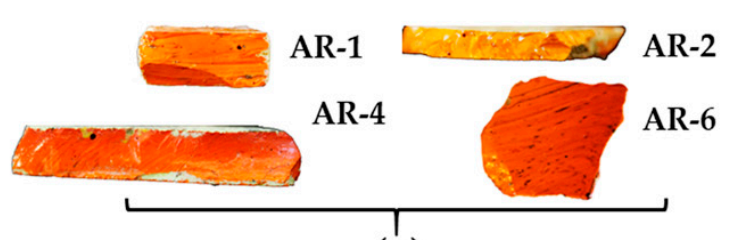

(e)

Figure 2. Samples of red sectilia from the Gorga collection: (a) Gr-1; (b) Gr-2; (c) Gr-3; (d) Gr-4; (e) Gr-5.

\subsubsection{Optical Microscopy}

The samples included in Gr-1 were characterized by a noticeable heterogeneity, where several layers of orange and dark red hues formed (Figure 3a,b). By means of naked eyes observation, dark transparent layers were observed, which seemed to not contain particles, when observed through a microscope, and through a very thin section, they resembled greenish transparent glass. The reddish-brown samples (Gr-2) looked homogenous, and some black inclusions were encountered. In samples R10, R17 and R21, numerous glittering crystals (triangle, hexagon), approximately around $50 \mu \mathrm{m}$ in size were observed (Figure 3c,d). The heterogeneous red-banded samples (Gr-3) were formed by large dark transparent zones and opaque red layers (Figure 3e,f).
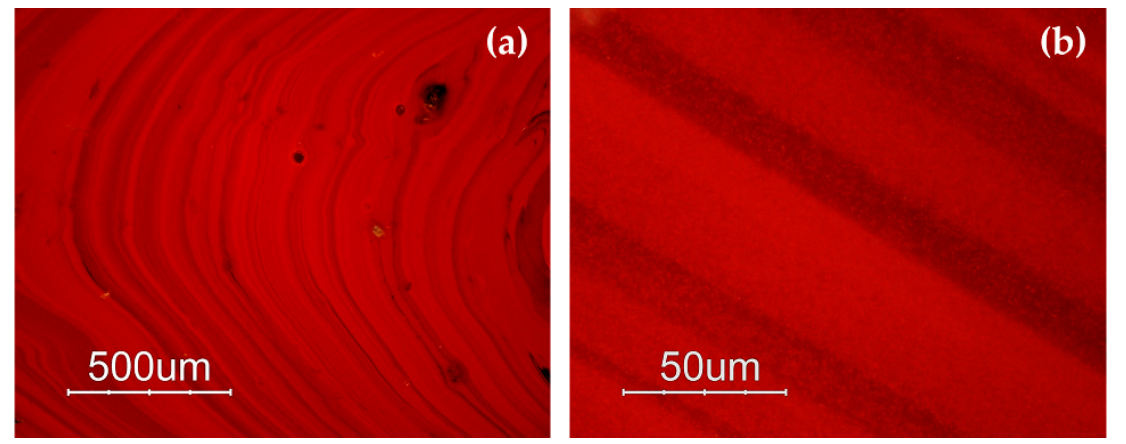

Figure 3. Cont. 

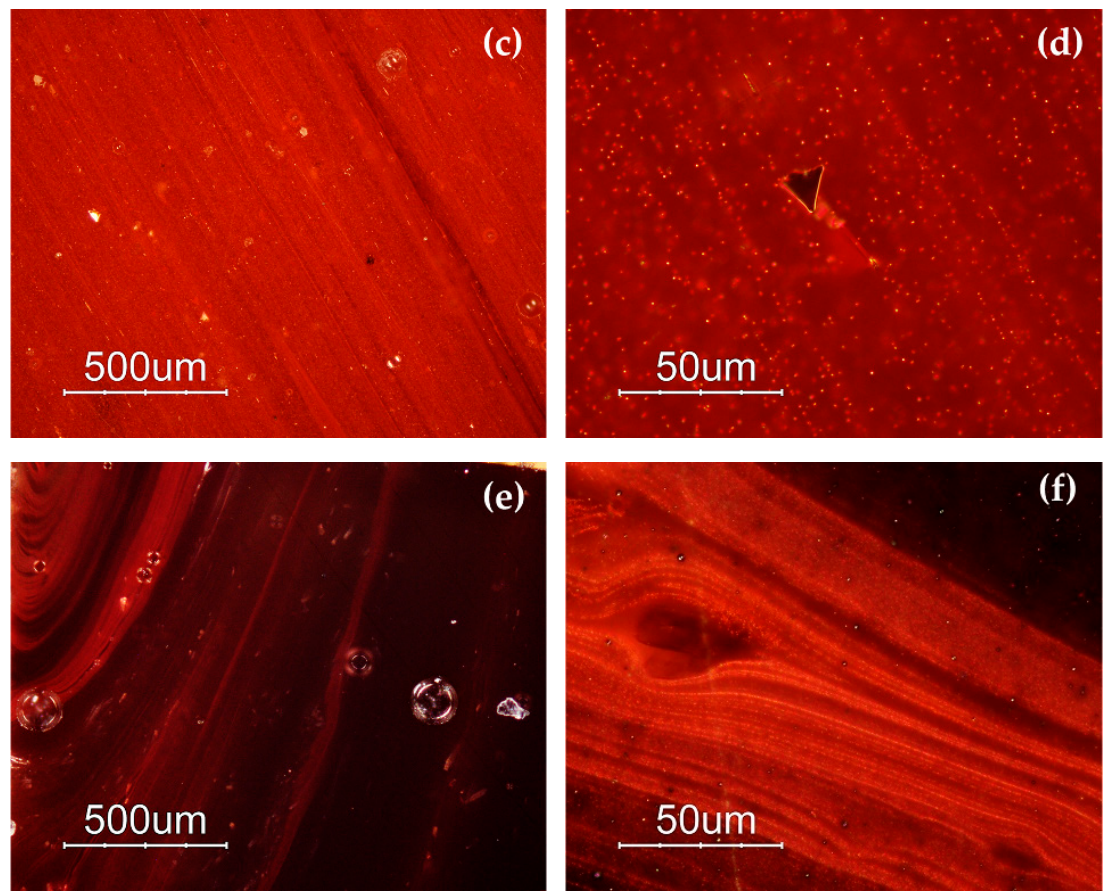

Figure 3. Optical micrographs in dark field objective: layers of different red hues in sample R4 (a,b); sample R10 (c) and sparkling crystals less than $50 \mu \mathrm{m}$ in sample R17 (d); several red bands are present in sample R1 (e,f).

The samples of the Gr-4 group had a homogeneous aspect and well-developed red dendritic crystals embedded in a colourless glass matrix were observed (Figure 4). The number and the dimensions of these crystals were slightly different in each sample, forming lighter (R13) (Figure 4c) and darker hues (R12) (Figure 4a) within this group. These features were comparable with the red type sealing wax.
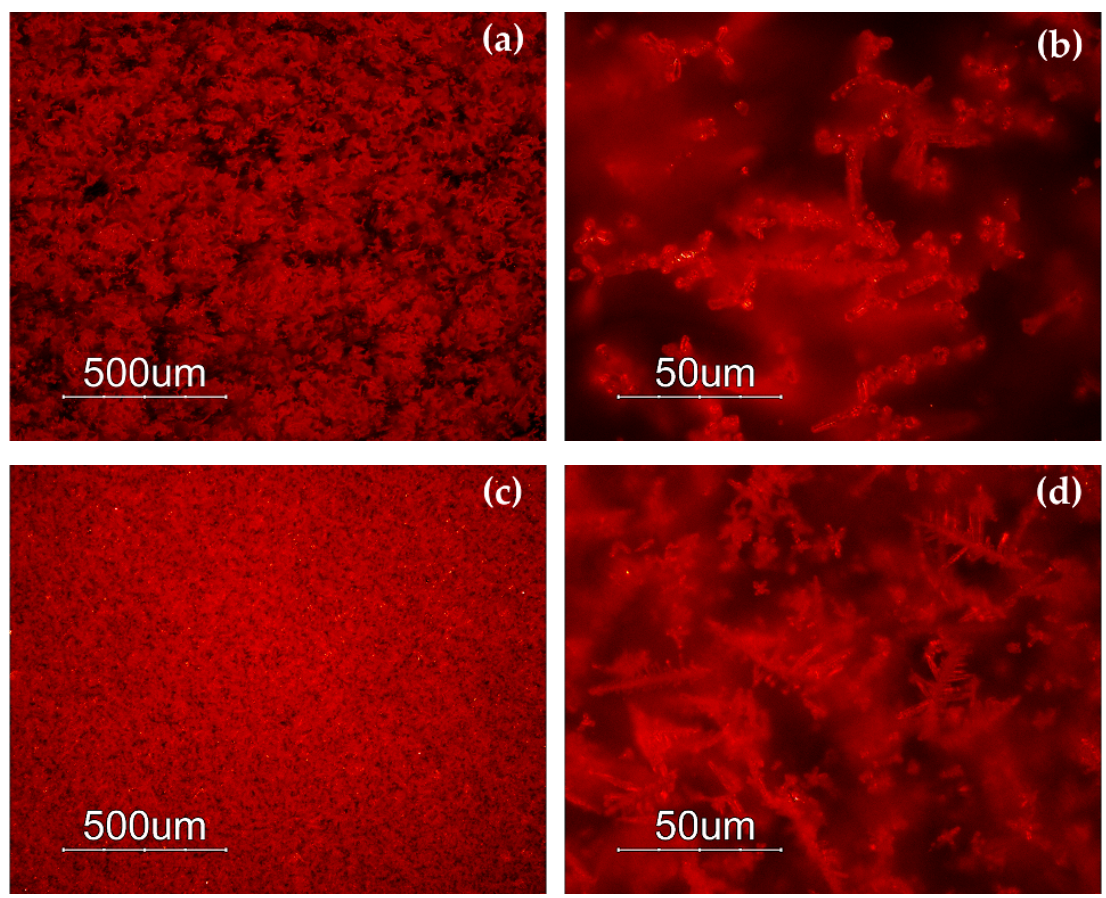

Figure 4. Optical micrographs in dark field objective: dendritic crystals embedded in the glass matrix in sample R12 (a,b) and R13 (c,d). 
Different hues were exhibited by the orange samples (Gr-5): yellowish orange AR1 and AR2 (Figure 5a,b), and reddish orange AR4 and AR6 (Figure 5c,d). Samples AR2 and AR6 look homogeneous, while the other samples showed the presence of reddish layers (Figure 5a-d).
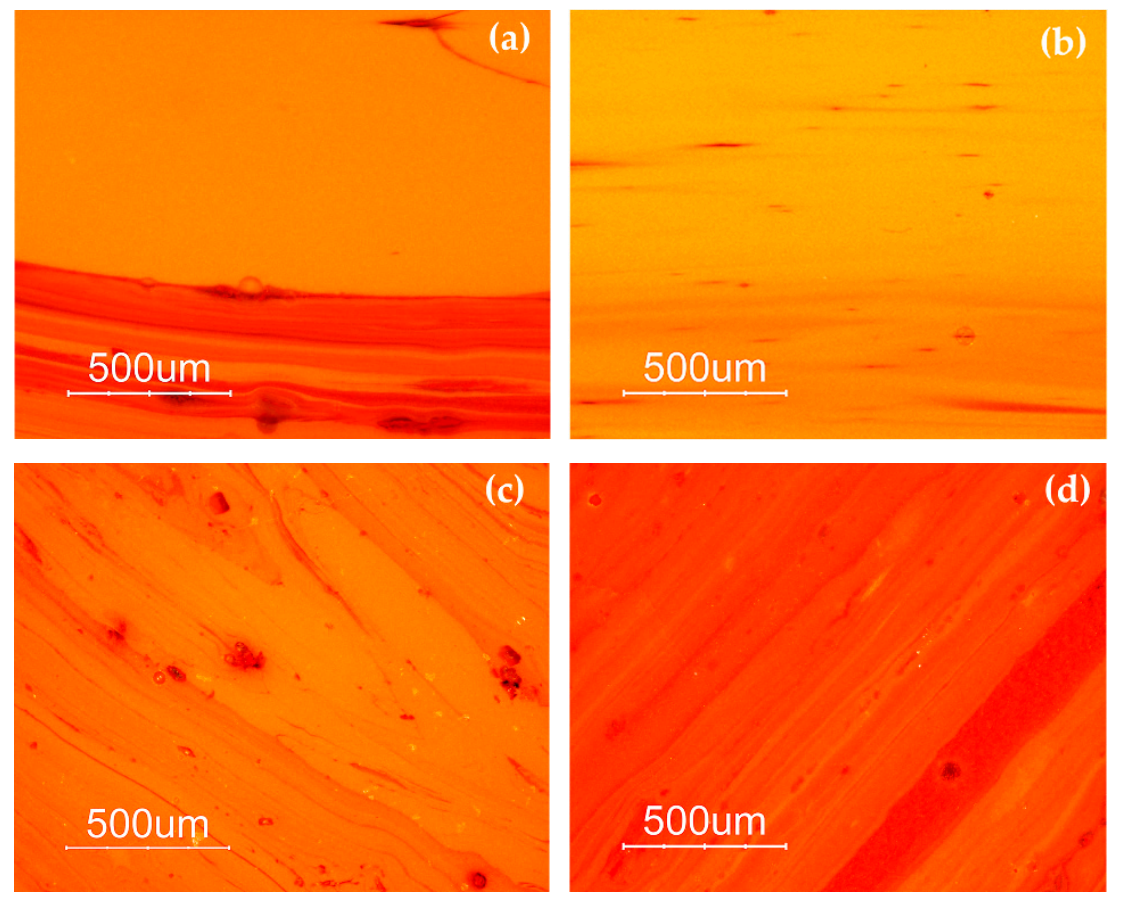

Figure 5. Optical micrographs in dark field objective: AR1 (a); AR2 (b); AR6 (c) AR4 (d).

\subsubsection{UV-Vis Reflectance Spectroscopy with Optical Fibres (FORS)}

The FORS spectroscopy helped to discriminate the red hues through the reflectance percentage and the calculation of the inflection points, which corresponded to the maximum of the first derivative in the reflectance spectra $[60,61]$.

The samples of the Gr-1 group (Figure 6a) showed an inflection point between 579 and $588 \mathrm{~nm}$ (Figure $6 b$ ), which is typical of a red colour, and the different reflectance percentage observed in the range between 650 and $780 \mathrm{~nm}$, makes some of them slightly lighter than others. The value of the inflection point could be attributed to the presence of metallic copper $[60,62-66]$.

In the Gr-2 group, the reflectance spectra exhibited a different shape (Figure 6c), while the value of the first derivative was in a narrower range between 582 and $586 \mathrm{~nm}$ (Figure 6d), likely due to metallic copper nanoparticles. Moreover, the shape of the spectra, as well as the first derivative, showed a shoulder centred around $660 \mathrm{~nm}$, which could be indicative of several iron oxides present in the samples [67]. The Gr-2 group had a lower reflectance percentage than the Gr-1 group, which led to a darker hue. Moreover, two different sub-groups emerged, observing the range between 650 and $780 \mathrm{~nm}$, which moved R18-R19-R20-R21 toward lighter tonality, while R10 and R17 were darker than the previous samples.

Gr-3 samples (Figure 7) are very dark with extremely low reflectance values; however, by means of fibre optics it was possible to discriminate the reflectance spectra of opaque red and dark transparent layers in samples R1 and R22. In the opaque red layer, the first derivative exhibited an inflection point at ca $575 \mathrm{~nm}$, suggesting the presence of metallic copper nanoparticles (Figure 7b). An extremely weak inflection point at the same position was detected in the dark transparent layer, suggesting the presence of few copper nanoparticles (Figure 7d). 

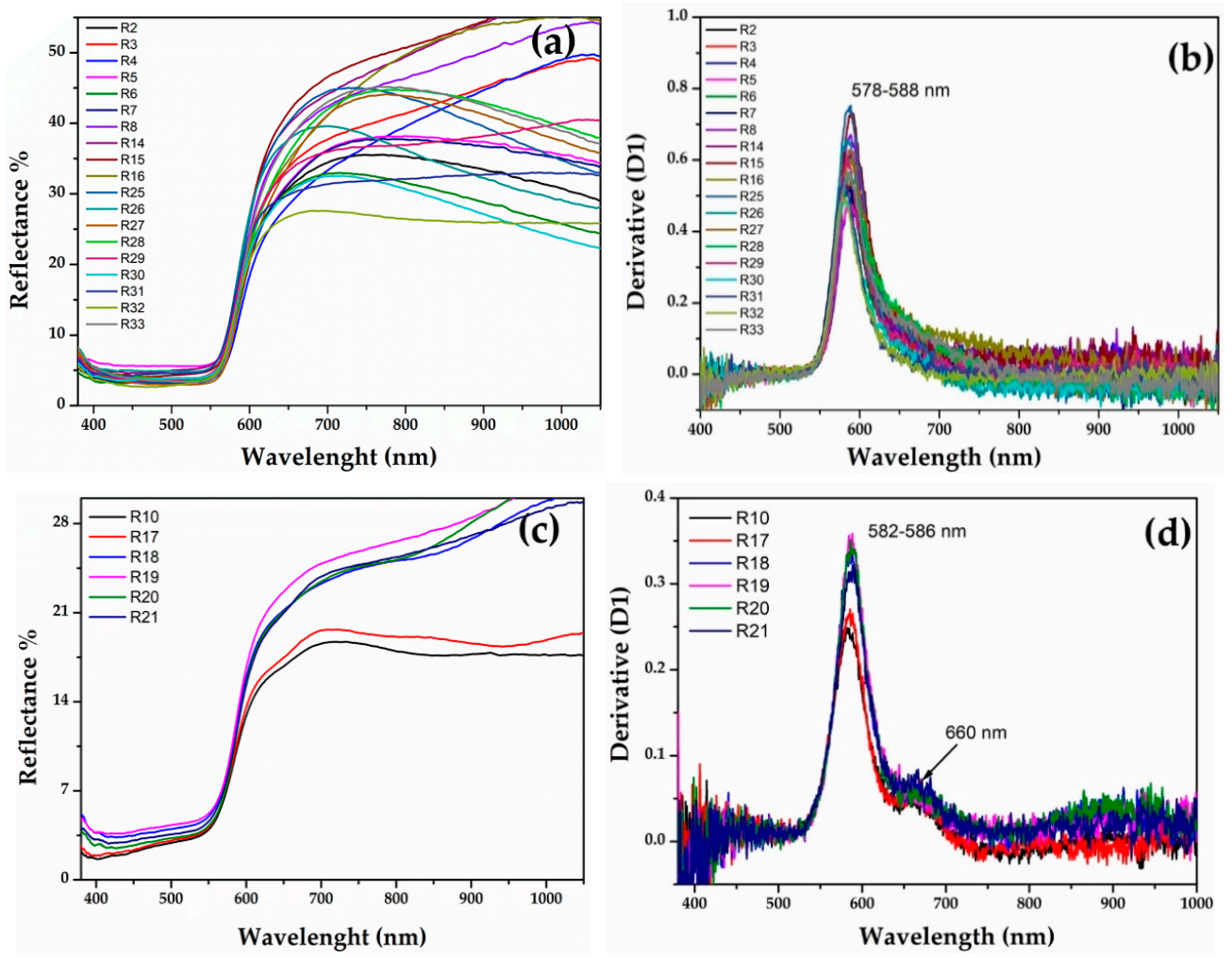

Figure 6. (a) Reflectance spectra of Gr-1 samples and the calculated first derivative (b); reflectance spectra of Gr-2 samples (c) and their first derivative (d).
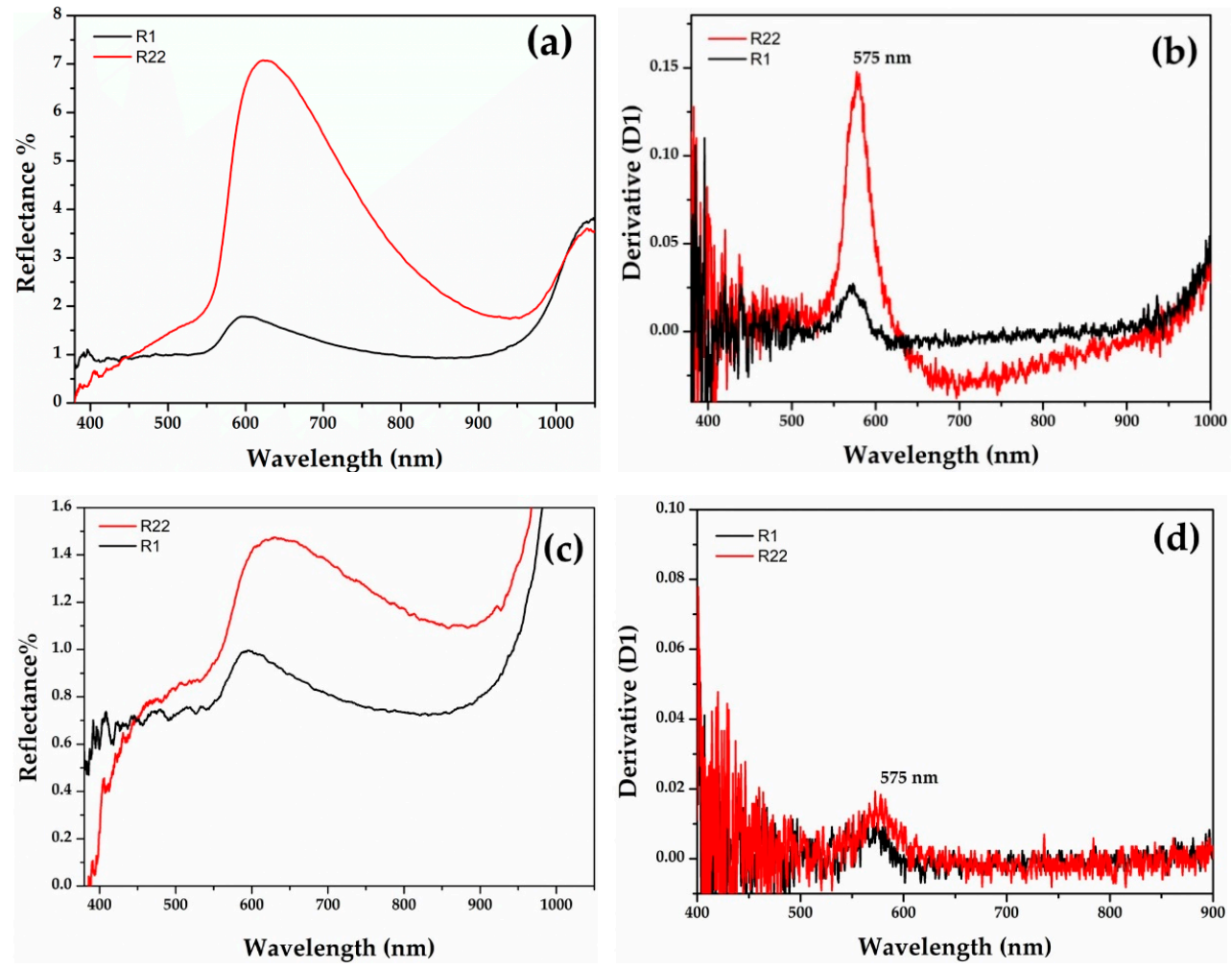

Figure 7. Reflectance spectra of Gr-3 groups with red (a) and dark transparent (c) layer. The first derivative of the red (b) and dark transparent layers (d). 
The sigmoid shapes with a steeper rise around the inflection point (Figure 8a) might indicate the presence of a semiconductor, such as cuprous oxide, in the Gr-4 group. This group exhibited reflectance values close to the Gr-1 group. The optical band gap was calculated by extrapolating the plot of the formula [55-57], and two values were obtained, for the four samples, at $c a 1.98$ and $2.08 \mathrm{eV}$, corresponding to an inflection point at $625 \mathrm{~nm}$ and $595 \mathrm{~nm}$, respectively (Figure 8b). Furthermore, these values were related to the presence of a cuprous oxide, which could be affected by the presence of some impurity.
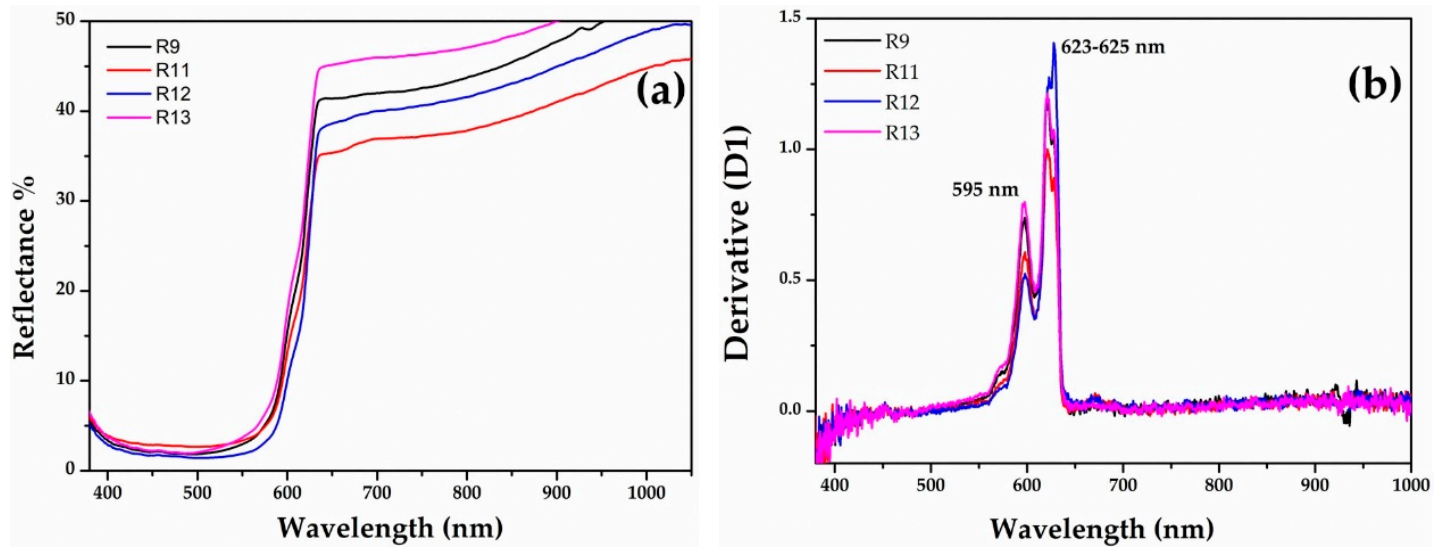

Figure 8. FORS spectra of Gr-4 samples: (a) reflectance spectra of Gr-4 samples in which cuprous oxide could be present as a colouring agent $(\mathbf{b})$ with their respective first derivative.

The spectra of the Gr-5 group (orange samples) showed two different hues, one more yellowish-orange (Figure 9a) and the second one reddish orange (Figure 9b). Sample AR4 exhibited a broad absorption band between 400 and $620 \mathrm{~nm}$, while the rest of the samples showed a narrow absorption before $500 \mathrm{~nm}$. The interpretation of these spectra was complicated. The energy band gaps of all samples revealed four values-2.56-2.13-2.08 and $1.98 \mathrm{eV}$ corresponding to absorption band a 482-583-595-623 nm (Figure 9c). These suggest the presence of nanocrystals of cuprite with different sizes and shapes $[58,68]$ and probably lead oxide [69].
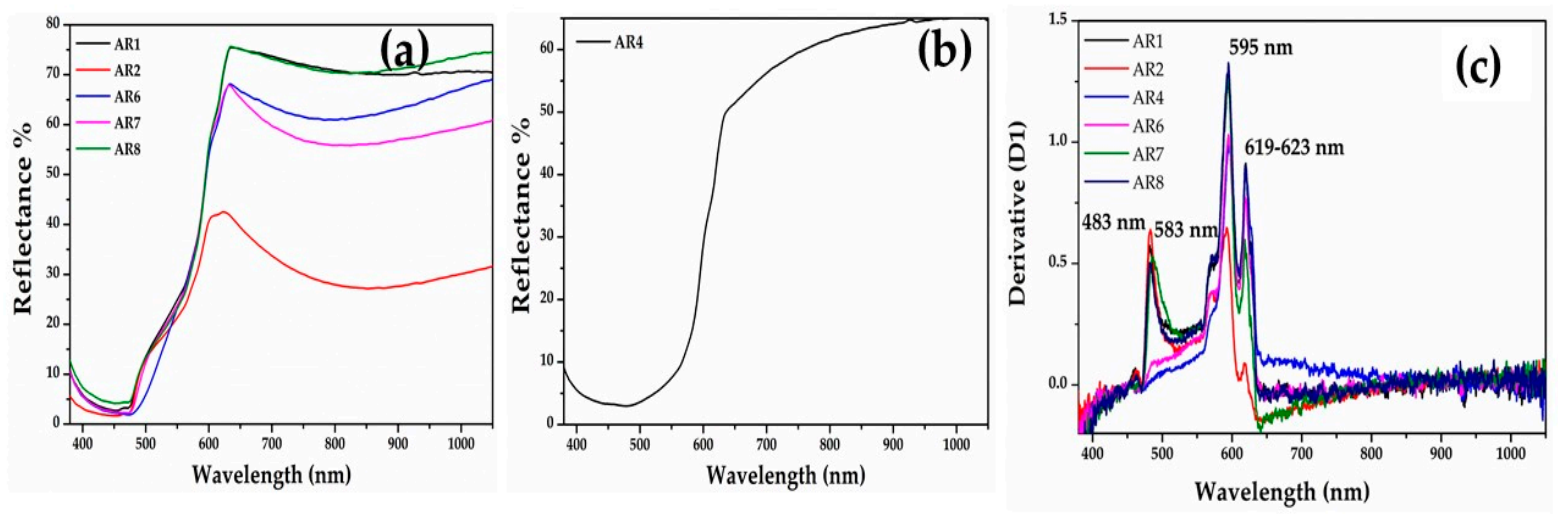

Figure 9. FORS spectra of orange samples. (a) Yellowish orange samples; (b) reddish orange sample (AR4); and (c) first derivative of the orange samples.

The probable presence of metallic copper and cuprite crystals could correspond to two different colouring technique.

\subsubsection{Colourimetry}

Through the colourimetric measurements, the samples and the groups were clearly identifiable in the 3D chart (Figure 10) although in some cases, these were divided by slight chromatic differences 
(Table 2). Some of the Gr-1 group samples (R31, R32), as observed through the FORS analyses, moved toward more brownish coordinates with a slight decrease of the $a^{*}$ (20 and 21 , respectively) and $b^{*}$ (10.7-12, respectively) coordinate.

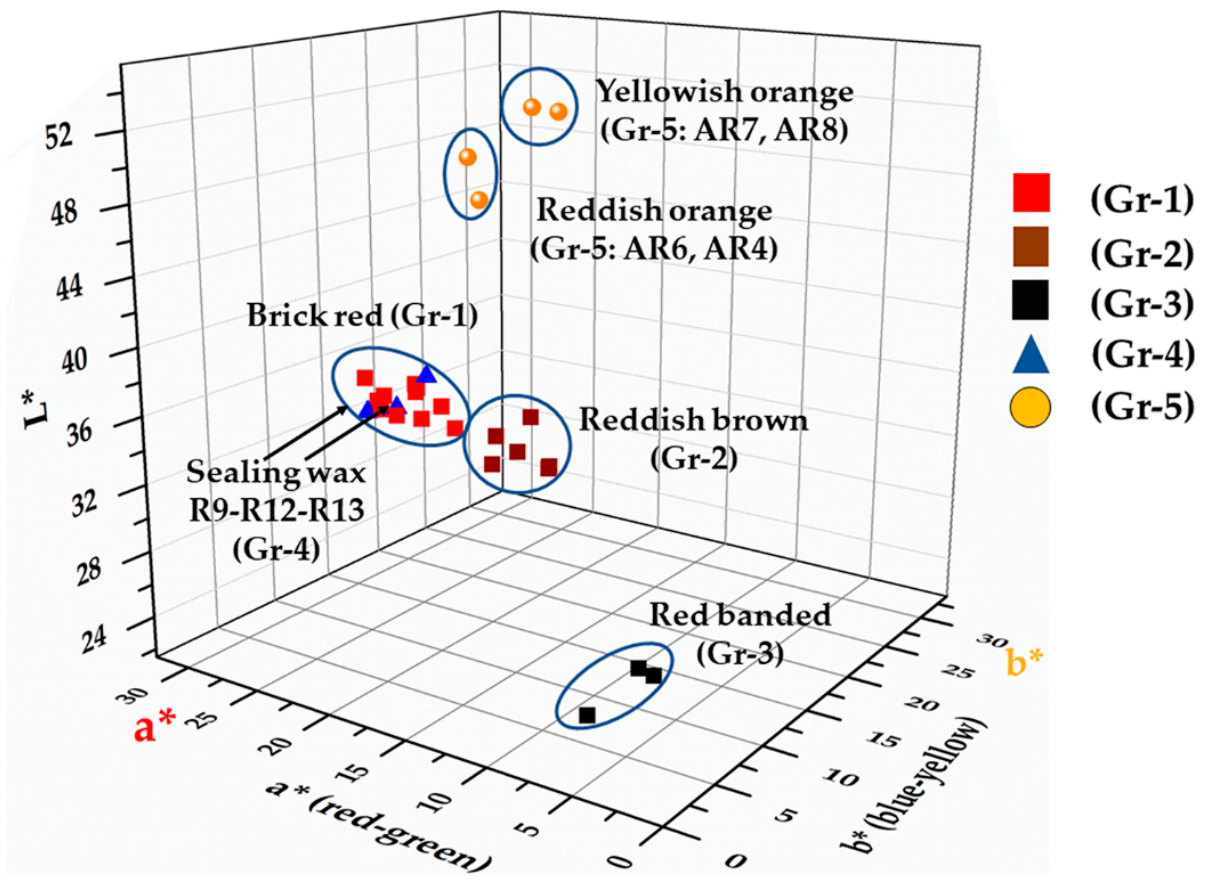

Figure 10. CIE Lab graphic representation: $L^{*} a^{*} b^{*}$ chromatic coordinates of the samples projected on the $L^{*} a^{*} b^{*}$ space.

Table 2. Average chromatic and colourimetric coordinates of the five groups.

\begin{tabular}{ccccc}
\hline \multirow{2}{*}{ Group } & Colour & \multicolumn{2}{c}{ Colorimetric Coordinates CIE L*a* $\mathbf{b}^{*}$} \\
\cline { 3 - 5 } & & $\mathbf{L}^{*}$ & $\mathbf{a}^{*}$ & $\mathbf{b}^{*}$ \\
\hline Gr-1 & Brick red & $34-36.3$ & $20.4-26.7$ & $10.7-13.3$ \\
Gr-2 & Reddish-brown & $33.7-36$ & $13.3-16.8$ & $9.2-10.6$ \\
Gr-3 & Red banded & $24-28$ & $1.3-6.3$ & $1.2-5.3$ \\
Gr-4 & Sealing wax & $34.6-40.5$ & $15.6-26$ & $7-11.2$ \\
Gr-5 & Yellowish orange & $49.3-50.1$ & $24.7-29$ & $29-34$ \\
Gr-5 & Reddish orange & $43.8-46.2$ & $30.3-32.4$ & $28.4-30.2$ \\
\hline
\end{tabular}

In the samples of Gr-2 group, the values of colourimetric coordinates decreased, especially a* (13.3-16.8) and $b^{*}(9.2-10.6)$, leading them towards a reddish-brown hue.

Samples of Gr-3 group showed a significant reduction of both colourimetric coordinate $\mathrm{a}^{*}$ and $\mathrm{b}^{*}$, in which the red and yellow part was almost absent, and an increase in the contribution of the green and blue part was observed, while the lowest brightness values moved these samples toward an extremely dark colour, almost black. Due to the small sizes of sample R1, it was not possible to measure the red and black layers separately, consequently, it seemed almost black ( $L^{*}: 24.3 ; a^{*}: 1.3 ; b^{*}$ : 1.2). In sample $R 22$, the red and black part were analysed, showing an increase of the $a^{*}(6.1$ and 5.3 , respectively) coordinate while the brightness was almost the same ( $L^{*}: 26.5$ and 24.3, respectively).

As was observed by the naked-eye and by the reflectance values, the samples of the Gr- 4 group were very close to those of Gr-1, making them almost identical. Furthermore, the R12 sample was a dark red, with low $a^{*}(15.7)$ and $b^{*}(7)$ values, while the brightness was higher ( $\left.\mathrm{L}^{*}: 40\right)$. Samples R9 and R13 were clearly distinct from R12, and showed a higher contribution of $a^{*}$ (23.5 and 26, respectively) and $b^{*}(10.8$ and 11.2 , respectively) chromatic coordinates. Probably the more intense red was due to the low values of the $b^{*}$ coordinate, which was higher in the Gr-1 group samples. 
Orange (Gr-5) samples split in two hues-reddish orange samples characterized by an increase of the red component (coordinate $\mathrm{a}^{*}$ : 30.3-32.4); while the yellowish-orange samples exhibited high brightness values ( $\left.L^{*}: 49.3-50.1\right)$ and higher values of the $b^{*}$ coordinate (29.4-34).

\subsection{Chemical Analyses}

The quantitative chemical composition of the analysed samples is reported in Table 3 In order to characterize the base glass composition, the element added for colouring or opacifying glass were removed ( $\left.\mathrm{PbO}, \mathrm{CuO}, \mathrm{SnO}_{2}, \mathrm{Sb}_{2} \mathrm{O}_{3}, \mathrm{ZnO}\right)$, leaving the elements that entered the glass from the sand and the fluxing agent. Afterwards, the chemical composition was re-calculated and normalized [70]. The obtained base glass composition would be functional to understand the colouring technique, and if the formation of colour was affected by the base glass composition. A strict comparison with the natron Roman groups present in the literature were out of the scope of this work.

\subsubsection{Base Glass Composition}

The glass composition identified two different types of soda-lime-silica glass. As showed in the bi-plot of Figure 11a, the five red hues were located in two main parts of the graphic. The samples of Gr-1 group were characterized by high contents of magnesium $(\mathrm{MgO} 3.1-3.3 \mathrm{wt} . \%)$ and potassium $\left(\mathrm{K}_{2} \mathrm{O}\right.$ 2.1-3.8 wt.\%). In this group, high phosphorus $\left(\mathrm{P}_{2} \mathrm{O}_{5}\right.$ 1.2-1.6 wt.\%) and calcium ( $\left.\mathrm{CaO} 12.1-12.8 \mathrm{wt} . \%\right)$ together with low sodium concentration $\left(\mathrm{Na}_{2} \mathrm{O}\right.$ 12.6-14.8 wt.\%) were also detected. These values suggest the use of a soda-plant ash as a fluxing agent [71].

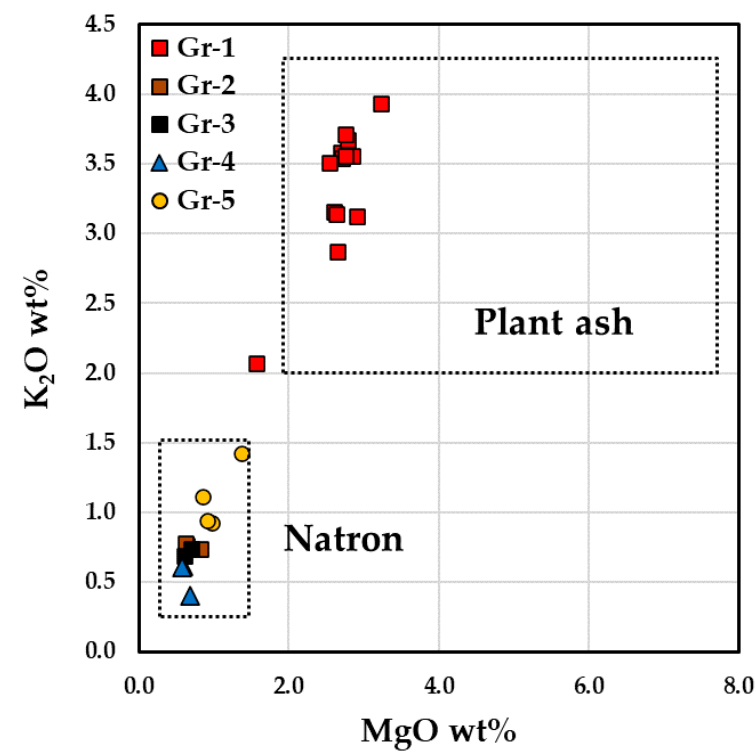

(a)

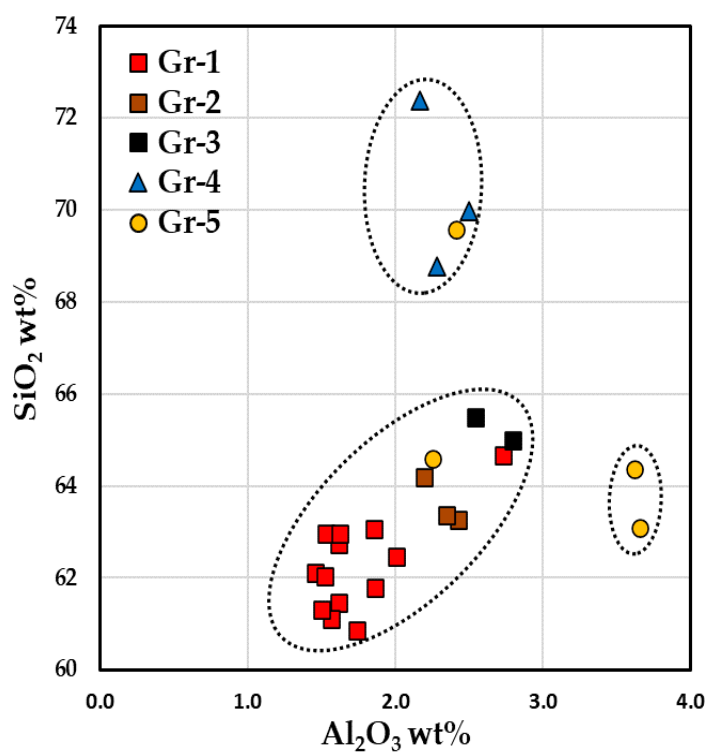

(b)

Figure 11. Bi-plot graph, reporting the concentrations from the reduced composition, of $\mathrm{MgO}$ vs. $\mathrm{K}_{2} \mathrm{O}$ (a), (b) $\mathrm{Al}_{2} \mathrm{O}_{3}$ vs. $\mathrm{SiO}_{2}$ of the base glass of the samples.

Samples of the Gr-2, Gr-3, Gr-4 and Gr-5 groups exhibit low concentrations of $\mathrm{MgO}$ and $\mathrm{K}_{2} \mathrm{O}$ (both lower than $1 \mathrm{wt} . \%$ ), as well as of $\mathrm{P}_{2} \mathrm{O}_{5}(<0.3 \mathrm{wt.} \%$ ) and $\mathrm{CaO}$ (from 6 to $8.1 \mathrm{wt} . \%$ ), while a higher sodium content $\left(\mathrm{Na}_{2} \mathrm{O} 15.8-18 \mathrm{wt} . \%\right)$ than $\mathrm{Gr}-1$ group was revealed. These samples were located in the lower left section of the diagram (Figure 11a) which belonged to the typical Roman natron glass. 
Table 3. Average quantitative chemical composition (wt.\% oxides) of the representative samples for each red hue (Gr-1, Gr-2, Gr-3, Gr-4, Gr5). With major and minor oxide in wt.\% oxide. * Samples analysed using EPMA, while the other samples were analysed by SEM-EDS. S.D.-Standard Deviation; five measurements were performed (at least) for each sample.

\begin{tabular}{|c|c|c|c|c|c|c|c|c|c|c|c|c|c|c|c|c|c|c|c|c|}
\hline Sample & Group & $\mathrm{SiO}_{2}$ & $\mathrm{Al}_{2} \mathrm{O}_{3}$ & $\mathrm{Na}_{2} \mathrm{O}$ & $\mathrm{K}_{2} \mathrm{O}$ & $\mathrm{CaO}$ & $\mathrm{MgO}$ & $\mathrm{SO}_{3}$ & $\mathbf{P}_{2} \mathrm{O}_{5}$ & $\mathrm{Cl}$ & $\mathrm{TiO}_{2}$ & $\mathrm{Fe}_{2} \mathrm{O}_{3}$ & $\mathrm{MnO}$ & $\mathrm{CuO}$ & $\mathrm{PbO}$ & $\mathrm{SnO}_{2}$ & $\mathrm{Sb}_{2} \mathrm{O}_{5}$ & $\mathrm{As}_{2} \mathrm{O}_{3}$ & $\mathrm{ZnO}$ & $\mathrm{BaO}$ \\
\hline \multirow[t]{2}{*}{$\mathrm{R}-2$ * } & Gr-1 & 59.0 & 1.7 & 12.9 & 3.1 & 11.5 & 3.0 & 0.23 & 1.1 & 0.73 & 0.12 & 1.3 & 0.40 & 2.0 & 1.3 & 1.2 & 0.12 & $<0.02$ & 0.07 & $<0.02$ \\
\hline & S.D. & 0.98 & 0.04 & 0.21 & 0.09 & 0.19 & 0.10 & 0.02 & 0.03 & 0.04 & 0.04 & 0.10 & 0.03 & 0.39 & 0.13 & 0.05 & 0.05 & & 0.05 & \\
\hline \multirow[t]{2}{*}{$\mathbf{R}-3$ * } & Gr-1 & 57.8 & 2.4 & 13.1 & 1.9 & 8.0 & 1.7 & 0.20 & 0.68 & 0.75 & 0.20 & 1.6 & 0.43 & 2.0 & 8.3 & 0.28 & 0.62 & 0.05 & 0.08 & $<0.02$ \\
\hline & S.D. & 0.73 & 0.04 & 0.91 & 0.05 & 0.46 & 0.04 & 0.03 & 0.03 & 0.01 & 0.02 & 0.13 & 0.02 & 0.13 & 0.13 & 0.03 & 0.05 & 0.02 & 0.13 & \\
\hline \multirow[t]{2}{*}{$\mathrm{R}-4^{*}$} & Gr-1 & 58.2 & 1.4 & 14.2 & 3.7 & 11.7 & 3.2 & 0.25 & 1.4 & 0.80 & 0.12 & 1.1 & 0.40 & 2.2 & 0.53 & 0.40 & 0.10 & 0.03 & 0.10 & $<0.02$ \\
\hline & S.D. & 0.16 & 0.03 & 0.15 & 0.03 & 0.40 & 0.07 & 0.01 & 0.02 & 0.01 & 0.03 & 0.07 & 0.03 & 0.20 & 0.07 & 0.05 & 0.05 & 0.02 & 0.02 & \\
\hline \multirow[t]{2}{*}{$\mathbf{R}-5$ * } & Gr-1 & 59.2 & 1.8 & 12.8 & 3.1 & 11.7 & 2.9 & 0.18 & 1.1 & 0.80 & 0.15 & 1.2 & 0.35 & 2.0 & 1.2 & 1.1 & 0.08 & $<0.02$ & 0.05 & 0.04 \\
\hline & S.D. & 0.09 & 0.01 & 0.06 & 0.02 & 0.10 & 0.03 & 0.04 & 0.03 & 0.01 & 0.03 & 0.02 & 0.04 & 0.08 & 0.03 & 0.02 & 0.05 & & 0.02 & 0.03 \\
\hline \multirow[t]{2}{*}{ R-6 * } & Gr-1 & 59.8 & 1.6 & 12.2 & 3.7 & 12.3 & 2.9 & 0.21 & 1.5 & 0.75 & 0.15 & 1.1 & 0.35 & 2.1 & 0.65 & 0.25 & 0.14 & $<0.02$ & 0.05 & 0.07 \\
\hline & S.D. & 0.23 & 0.02 & 0.10 & 0.04 & 0.21 & 0.05 & 0.03 & 0.03 & 0.04 & 0.02 & 0.04 & 0.01 & 0.10 & 0.05 & 0.06 & 0.05 & & 0.02 & 0.03 \\
\hline \multirow[t]{2}{*}{$\mathrm{R}-7^{*}$} & Gr-1 & 59.0 & 1.8 & 13.8 & 3.0 & 12.4 & 2.9 & 0.23 & 1.3 & 0.77 & 0.17 & 1.3 & 0.35 & 1.8 & 0.55 & 0.27 & 0.12 & $<0.02$ & 0.05 & 0.08 \\
\hline & S.D. & 0.47 & 0.77 & 0.26 & 0.23 & 1.41 & 0.19 & 0.03 & 0.04 & 0.21 & 0.08 & 0.40 & 0.02 & 0.31 & 0.17 & 0.08 & 0.05 & & 0.02 & 0.03 \\
\hline \multirow[t]{2}{*}{$\mathbf{R}-8$ * } & Gr-1 & 58.4 & 1.5 & 14.1 & 3.6 & 12.1 & 3.1 & 0.23 & 1.4 & 0.80 & 0.15 & 1.1 & 0.40 & 2.1 & 0.40 & 0.32 & 0.12 & $<0.02$ & $<0.02$ & 0.08 \\
\hline & S.D. & 1.35 & 0.08 & 0.79 & 0.24 & 1.06 & 0.22 & 0.04 & 0.05 & 0.07 & 0.02 & 0.10 & 0.02 & 0.37 & 0.06 & 0.02 & 0.05 & & & 0.03 \\
\hline \multirow[t]{2}{*}{ R14 } & Gr-1 & 58.8 & 1.4 & 14.3 & 3.4 & 11.4 & 2.6 & 0.32 & 1.1 & 0.83 & 0.11 & 1.2 & 0.35 & 2.8 & 0.26 & 0.60 & $<0.1$ & $<0.1$ & $<0.1$ & $<0.1$ \\
\hline & S.D. & 0.26 & 0.04 & 0.07 & 0.03 & 0.21 & 0.04 & 0.05 & 0.05 & 0.03 & 0.04 & 0.09 & 0.06 & 0.26 & 0.06 & 0.11 & & & & \\
\hline \multirow[t]{2}{*}{ R16 } & Gr-1 & 59.2 & 1.4 & 13.6 & 3.4 & 11.3 & 2.6 & 0.35 & 1.0 & 0.77 & 0.15 & 1.2 & 0.30 & 2.8 & 0.67 & 0.51 & 0.21 & $<0.1$ & $<0.1$ & $<0.1$ \\
\hline & S.D. & 0.60 & 0.09 & 0.24 & 0.09 & 0.51 & 0.05 & 0.07 & 0.08 & 0.04 & 0.06 & 0.09 & 0.08 & 0.32 & 0.09 & 0.13 & 0.13 & & & \\
\hline \multirow[t]{2}{*}{ R26 } & Gr-1 & 60.8 & 1.4 & 13.1 & 3.4 & 11.5 & 2.4 & 0.25 & 1.2 & 0.82 & 0.09 & 1.1 & 0.35 & 2.3 & 0.31 & 0.46 & $<0.1$ & $<0.1$ & $<0.1$ & $<0.1$ \\
\hline & S.D. & 0.24 & 0.04 & 0.06 & 0.04 & 0.15 & 0.05 & 0.05 & 0.06 & 0.02 & 0.06 & 0.07 & 0.09 & 0.05 & 0.06 & 0.11 & & & & \\
\hline \multirow[t]{2}{*}{ R27 } & Gr-1 & 59.2 & 1.5 & 12.8 & 2.9 & 11.3 & 2.4 & 0.29 & 0.90 & 0.78 & 0.12 & 1.4 & 0.33 & 2.9 & 1.1 & 1.2 & 0.18 & $<0.1$ & $<0.1$ & $<0.1$ \\
\hline & S.D. & 0.41 & 0.07 & 0.07 & 0.06 & 0.13 & 0.02 & 0.13 & 0.09 & 0.04 & 0.08 & 0.13 & 0.09 & 0.38 & 0.11 & 0.13 & 0.14 & & & \\
\hline \multirow[t]{2}{*}{ R31 } & Gr-1 & 57.7 & 1.6 & 11.1 & 3.5 & 12.1 & 2.6 & 0.15 & 1.3 & 0.64 & 0.18 & 3.3 & 0.56 & 1.8 & 1.9 & 0.88 & $<0.1$ & $<0.1$ & $<0.1$ & $<0.1$ \\
\hline & S.D. & 0.21 & 0.05 & 0.05 & 0.04 & 0.09 & 0.03 & 0.03 & 0.04 & 0.04 & 0.08 & 0.09 & 0.12 & 0.09 & 0.08 & 0.07 & & & & \\
\hline \multirow[t]{2}{*}{ R33 } & Gr-1 & 58.3 & 1.4 & 11.4 & 3.7 & 11.8 & 3.0 & 0.35 & 1.4 & 0.65 & 0.14 & 1.3 & 0.41 & 2.8 & 1.5 & 0.87 & 0.30 & $<0.1$ & $<0.1$ & $<0.1$ \\
\hline & S.D. & 0.76 & 0.11 & 0.08 & 0.09 & 0.26 & 0.04 & 0.07 & 0.09 & 0.03 & 0.06 & 0.13 & 0.08 & 0.34 & 0.20 & 0.37 & 0.13 & & & \\
\hline \multirow[t]{2}{*}{$\mathrm{R}-10$ * } & Gr-2 & 60.5 & 2.5 & 18.0 & 0.75 & 5.9 & 0.96 & 0.25 & 0.23 & 1.1 & 0.15 & 4.7 & 0.53 & 2.5 & 1.0 & 0.30 & 0.35 & 0.10 & $<0.02$ & 0.05 \\
\hline & S.D. & 0.17 & 0.02 & 0.02 & 0.01 & 0.02 & 0.01 & 0.01 & 0.02 & 0.01 & 0.01 & 0.02 & 0.02 & 0.21 & 0.03 & 0.04 & 0.17 & 0.02 & & 0.03 \\
\hline \multirow[t]{2}{*}{ R17 } & Gr-2 & 60.2 & 2.2 & 18.3 & 0.72 & 5.8 & 0.60 & 0.49 & 0.17 & 1.1 & 0.18 & 4.7 & 0.50 & 3.2 & 1.0 & 0.48 & $<0.1$ & $<0.1$ & $<0.1$ & $<0.1$ \\
\hline & S.D. & 0.21 & 0.12 & 0.09 & 0.04 & 0.05 & 0.05 & 0.08 & 0.03 & 0.02 & 0.06 & 0.07 & 0.04 & 0.22 & 0.05 & 0.15 & & & & \\
\hline \multirow[t]{2}{*}{ R19 } & Gr-2 & 60.5 & 2.1 & 17.0 & 0.73 & 6.1 & 0.58 & 0.72 & 0.13 & 0.89 & 0.09 & 5.0 & 0.38 & 3.3 & 1.1 & 0.46 & 0.68 & 0.13 & $<0.1$ & $<0.1$ \\
\hline & S.D. & 0.27 & 0.05 & 0.06 & 0.02 & 0.09 & 0.04 & 0.05 & 0.06 & 0.02 & 0.03 & 0.08 & 0.07 & 0.27 & 0.07 & 0.09 & 0.09 & 0.07 & & \\
\hline
\end{tabular}


Table 3. Cont.

\begin{tabular}{|c|c|c|c|c|c|c|c|c|c|c|c|c|c|c|c|c|c|c|c|c|}
\hline Sample & Group & $\mathrm{SiO}_{2}$ & $\mathrm{Al}_{2} \mathrm{O}_{3}$ & $\mathrm{Na}_{2} \mathrm{O}$ & $\mathrm{K}_{2} \mathrm{O}$ & $\mathrm{CaO}$ & $\mathrm{MgO}$ & $\mathrm{SO}_{3}$ & $\mathrm{P}_{2} \mathrm{O}_{5}$ & $\mathrm{Cl}$ & $\mathrm{TiO}_{2}$ & $\mathrm{Fe}_{2} \mathrm{O}_{3}$ & $\mathrm{MnO}$ & $\mathrm{CuO}$ & $\mathrm{PbO}$ & $\mathrm{SnO}_{2}$ & $\mathrm{Sb}_{2} \mathrm{O}_{5}$ & $\mathrm{As}_{2} \mathrm{O}_{3}$ & $\mathrm{ZnO}$ & $\mathrm{BaO}$ \\
\hline \multirow[t]{2}{*}{$\mathrm{R}-1$ * } & Gr-3 & 64.6 & 2.8 & 15.5 & 0.74 & 8.0 & 0.80 & 0.17 & 0.16 & 0.72 & 0.12 & 4.5 & 0.60 & 0.27 & 0.45 & 0.04 & 0.40 & 0.05 & 0.05 & $<0.02$ \\
\hline & S.D. & 0.32 & 0.03 & 0.02 & 0.06 & 0.05 & 0.03 & 0.04 & 0.02 & 0.12 & 0.02 & 0.34 & 0.15 & 0.02 & 0.03 & 0.02 & 0.05 & 0.03 & 0.01 & \\
\hline \multirow[t]{2}{*}{ R1 red } & Gr-3 & 63.8 & 2.9 & 16.3 & 0.70 & 8.0 & 0.70 & 0.37 & 0.08 & 0.41 & 0.12 & 5.4 & 0.55 & 0.10 & 0.14 & 0.39 & $<0.1$ & $<0.1$ & $<0.1$ & $<0.1$ \\
\hline & S.D. & 0.02 & 0.02 & 0.02 & 0.07 & 0.04 & 0.03 & 0.06 & 0.01 & 0.05 & 0.01 & 0.03 & 0.09 & 0.00 & 0.03 & 0.001 & & & & \\
\hline \multirow[t]{2}{*}{ R1 black } & Gr-3 & 64.4 & 2.8 & 16.4 & 0.70 & 8.0 & 0.70 & 0.30 & 0.03 & 0.61 & 0.12 & 4.6 & 0.58 & 0.11 & 0.15 & 0.35 & $<0.1$ & $<0.1$ & $<0.1$ & $<0.1$ \\
\hline & S.D. & 0.07 & 0.01 & 0.02 & 0.05 & 0.04 & 0.00 & 0.02 & 0.02 & 0.01 & 0.02 & 0.15 & 0.05 & 0.02 & 0.02 & 0.02 & & & & \\
\hline \multirow[t]{2}{*}{$\mathrm{R} 22$} & Gr-3 & 64.9 & 2.5 & 16.2 & 0.68 & 7.9 & 0.60 & 0.51 & 0.19 & 0.91 & 0.08 & 3.9 & 0.68 & 0.31 & 0.20 & 0.22 & $<0.1$ & $<0.1$ & $<0.1$ & $<0.1$ \\
\hline & S.D. & 0.71 & 0.07 & 0.09 & 0.06 & 0.05 & 0.04 & 0.05 & 0.04 & 0.03 & 0.07 & 0.64 & 0.15 & 0.16 & 0.09 & 0.16 & & & & \\
\hline \multirow[t]{2}{*}{ R22 red } & Gr-3 & 64.3 & 2.5 & 16.3 & 0.67 & 7.8 & 0.61 & 0.52 & 0.17 & 0.88 & 0.08 & 4.5 & 0.55 & 0.38 & 0.26 & 0.24 & $<0.1$ & $<0.1$ & $<0.1$ & $<0.1$ \\
\hline & S.D. & 0.21 & 0.07 & 0.08 & 0.07 & 0.04 & 0.04 & 0.03 & 0.03 & 0.02 & 0.09 & 0.16 & 0.09 & 0.12 & 0.04 & 0.16 & & & & \\
\hline \multirow[t]{2}{*}{ R22 black } & Gr-3 & 65.6 & 2.5 & 16.1 & 0.69 & 7.9 & 0.59 & 0.50 & 0.2 & 0.94 & 0.08 & 3.3 & 0.81 & 0.24 & 0.14 & 0.19 & $<0.1$ & $<0.1$ & $<0.1$ & $<0.1$ \\
\hline & S.D. & 0.19 & 0.07 & 0.02 & 0.05 & 0.04 & 0.04 & 0.06 & 0.04 & 0.02 & 0.06 & 0.07 & 0.05 & 0.17 & 0.08 & 0.15 & & & & \\
\hline \multirow[t]{2}{*}{$\mathrm{R}-9$ * } & Gr-4 & 43.5 & 1.6 & 9.5 & 0.52 & 5.0 & 0.40 & 0.40 & 0.09 & 0.45 & 0.10 & 0.45 & 0.13 & 7.7 & 28.5 & 0.25 & 1.3 & $<0.02$ & $<0.02$ & $<0.02$ \\
\hline & S.D. & 0.49 & 0.02 & 0.05 & 0.02 & 0.15 & 0.03 & 0.04 & 0.00 & 0.02 & 0.00 & 0.02 & 0.02 & 1.39 & 0.79 & 0.05 & 0.12 & & & \\
\hline \multirow[t]{2}{*}{ R11 } & Gr-4 & 41.1 & 1.2 & 9.2 & 0.23 & 2.9 & 0.39 & $<0.1$ & 0.10 & 0.67 & 0.17 & 0.69 & 0.05 & 11.7 & 30.4 & 0.14 & 0.84 & $<0.1$ & $<0.1$ & $<0.1$ \\
\hline & S.D. & 1.20 & 0.09 & 0.13 & 0.05 & 0.17 & 0.03 & & 0.05 & 0.05 & 0.08 & 0.10 & 0.06 & 2.73 & 1.37 & 0.12 & 0.16 & & & \\
\hline \multirow[t]{2}{*}{ R12 } & Gr-4 & 42.8 & 1.5 & 10.7 & 0.37 & 3.9 & 0.35 & $<0.1$ & 0.06 & 0.57 & 0.02 & 0.63 & 0.17 & 9.6 & 28 & 0.24 & 0.87 & & & \\
\hline & S.D. & 0.82 & 0.06 & 0.12 & 0.04 & 0.11 & 0.05 & & 0.05 & 0.05 & 0.02 & 0.08 & 0.10 & 1.70 & 0.64 & 0.09 & 0.04 & & & \\
\hline \multirow[t]{2}{*}{ AR-1 * } & Gr-5 & 44.8 & 2.8 & 10.9 & 0.71 & 6.8 & 0.80 & 0.28 & 0.19 & 0.50 & 0.20 & 1.5 & 0.20 & 8.5 & 20.0 & 0.80 & $<0.02$ & $<0.02$ & $<0.02$ & $<0.02$ \\
\hline & S.D. & 1.27 & 0.04 & 0.21 & 0.01 & 0.06 & 0.02 & 0.03 & 0.05 & 0.12 & 0.03 & 0.05 & 0.04 & 2.02 & 0.31 & 0.04 & & & & \\
\hline \multirow[t]{2}{*}{ AR-2 * } & Gr-5 & 46.0 & 1.8 & 9.5 & 0.74 & 4.2 & 0.70 & 0.42 & 0.21 & 0.50 & 0.09 & 0.70 & 0.35 & 9.8 & 22.4 & 1.1 & 1.3 & 0.05 & 0.04 & $<0.02$ \\
\hline & S.D. & 1.37 & 0.09 & 0.20 & 0.06 & 0.31 & 0.05 & 0.04 & 0.03 & 0.01 & 0.02 & 3.77 & 0.05 & 2.13 & 1.41 & 0.08 & 0.14 & 0.01 & 0.19 & \\
\hline \multirow[t]{2}{*}{$\mathrm{AR}-4$ * } & Gr-5 & 50.8 & 1.9 & 13.0 & 1.2 & 6.7 & 1.3 & 0.57 & 0.40 & 0.60 & 0.18 & 1.5 & 0.27 & 11.0 & 8.0 & 1.2 & 1.2 & 0.05 & 0.07 & $<0.02$ \\
\hline & S.D. & 1.66 & 0.12 & 0.34 & 0.07 & 0.68 & 0.05 & 0.11 & 0.04 & 0.10 & 0.04 & 0.10 & 0.08 & 2.49 & 0.39 & 0.07 & 0.14 & 0.05 & 0.16 & \\
\hline \multirow[t]{2}{*}{ AR8 red } & Gr-5 & 45.6 & 2.3 & 10.8 & 0.80 & 7.3 & 0.61 & $<0.1$ & 0.23 & 0.99 & 0.21 & 1.7 & 0.25 & 7.8 & 19.4 & 1.2 & 0.33 & $<0.1$ & $<0.1$ & $<0.1$ \\
\hline & S.D. & 0.20 & 0.09 & 0.13 & 0.06 & 0.13 & 0.06 & & 0.06 & 0.06 & 0.05 & 0.08 & 0.13 & 0.08 & 0.10 & 0.15 & 0.09 & & & \\
\hline \multirow[t]{2}{*}{ AR8 yellow } & Gr-5 & 45.8 & 2.6 & 10.6 & 0.80 & 7.3 & 0.59 & $<0.1$ & 0.21 & 0.93 & 0.21 & 1.7 & 0.25 & 8.1 & 19.4 & 1.1 & 0.26 & $<0.1$ & $<0.1$ & $<0.1$ \\
\hline & S.D. & 0.16 & 0.11 & 0.11 & 0.08 & 0.07 & 0.04 & & 0.09 & 0.09 & 0.13 & 0.05 & 0.14 & 0.14 & 0.26 & 0.18 & 0.17 & & & \\
\hline
\end{tabular}


Gr-1 group exhibited low contents of alumina and silica compared to the samples of the Gr-2 and Gr-3 groups, however, the former network was supplied from a similar silica source. Sample R3 of the Gr-1 group was different from the other brick red samples, showing low magnesium ( $\mathrm{MgO}$ $1.9 \mathrm{wt} . \%)$ and calcium (CaO $8.9 \mathrm{wt} . \%)$ values, with higher contents of silica and alumina (Figure 11b). High levels of silica were detected in the Gr-4 group and in one orange glass. Two samples of the Gr-5 group seemed to be produced with the same sand of Gr-2 and Gr-4 groups, while the other two samples (AR1 and AR8) were located in distinct area of the graph, with a higher alumina content.

\subsubsection{Bulk Composition}

Taking into account the concentration of copper and lead, the five groups could be gathered in two main categories-high concentrations of copper $(\mathrm{CuO}>5 \mathrm{wt} . \%)$ and lead $(\mathrm{PbO}>15 \mathrm{wt} . \%)$; low contents of copper $(\mathrm{CuO}<5 \mathrm{wt} . \%)$ and lead $(\mathrm{PbO}<15 \mathrm{wt} . \%)$ (see Table 4). A concentration of copper lower than $5 \mathrm{wt}$.\% was observed in the Gr-1, Gr-2 and Gr-3. These groups showed different concentration of copper correlated with differences in the iron contents. In the Gr-1 samples, low levels of iron and moderate copper contents were detected (respectively, $\mathrm{Fe}_{2} \mathrm{O}_{3} 1.1-1.3 \mathrm{wt} \%$; $\mathrm{CuO} 1.8-2.2 \mathrm{wt} . \%$ ), except in sample R31 in which the content of iron increased beyond the $3 \mathrm{wt} . \%\left(\mathrm{Fe}_{2} \mathrm{O}_{3} 3.3 \mathrm{wt} . \%\right)$, as well the colour moving toward more reddish brown hue. The Gr-2 group presented higher amount of iron and copper $\left(\mathrm{Fe}_{2} \mathrm{O}_{3}\right.$ 4.5-5.0 wt.\%; $\mathrm{CuO} 2.7-3.3 \mathrm{wt}$.\%); while in the Gr-3 group, the iron content was close to the samples of $\mathrm{Gr}-2\left(\mathrm{Fe}_{2} \mathrm{O}_{3} 4.5 \mathrm{wt} . \%\right)$, however, the concentration of copper was drastically reduced $(\mathrm{CuO} 0.3 \mathrm{wt} . \%)$. Lead contents were very low in the $\mathrm{Gr}-3$ group (PbO $0.3 \mathrm{wt} . \%)$, variable in the $\mathrm{Gr}-1$ group (PbO 0.4-2.0 wt.\%), and constant around $1.1 \mathrm{wt} . \%$ in the Gr-2 group. Tin contents were higher than $1 \mathrm{wt} . \%$, only in three samples of the Gr-1 group (R2, R5 and R27)

Table 4. Average chemical composition of copper $(\mathrm{CuO})$, lead $(\mathrm{PbO})$, iron $\left(\mathrm{Fe}_{2} \mathrm{O}_{3}\right)$, tin $\left(\mathrm{SnO}_{2}\right)$ and antimony $\left(\mathrm{Sb}_{2} \mathrm{O}_{5}\right)$ oxides for each hue group, with the respective standard deviation values. S.D.- -standard deviation.

\begin{tabular}{ccccccccccc}
\hline Group & $\mathbf{C u O}$ & S.D. & $\mathbf{P b O}$ & S.D. & $\mathrm{Fe}_{\mathbf{2}} \mathbf{O}_{\mathbf{3}}$ & S.D. & $\mathbf{S n O}_{2}$ & S.D. & $\mathbf{S b}_{2} \mathrm{O}_{5}$ & S.D. \\
\hline Gr-1 & 2.3 & 0.39 & 1.5 & 2.0 & 1.4 & 0.56 & 0.7 & 0.36 & 0.2 & 0.15 \\
$\mathrm{Gr}-2$ & 3.1 & 0.36 & 1.1 & 0.06 & 4.8 & 0.14 & 0.4 & 0.08 & 0.5 & 0.17 \\
$\mathrm{Gr}-3$ & 0.3 & 0.02 & 0.3 & 0.13 & 4.2 & 0.29 & 0.1 & 0.09 & 0.4 & 0.00 \\
$\mathrm{Gr}-4$ & 9.7 & 1.6 & 29.0 & 1.0 & 0.6 & 0.10 & 0.2 & 0.05 & 1.0 & 0.23 \\
Gr-5 & 9.3 & 1.2 & 17.5 & 5.6 & 1.4 & 0.38 & 1.1 & 0.15 & 0.9 & 0.42 \\
\hline
\end{tabular}

Gr-4 and Gr-5 groups were very rich in lead as well in the content of copper, which was higher than $5 \mathrm{wt} . \%$. The concentrations of copper (CuO 7.7-11.7 wt.\%), lead (PbO 28.5-30.0 wt.\%) and antimony $\left(\mathrm{Sb}_{2} \mathrm{O}_{3}\right.$ 0.84-1.3 wt.\%) detected in the samples of the $\mathrm{Gr}-4$ group were very close to the sealing wax red glass. Moreover, a drastic decrease of iron content $\left(\mathrm{Fe}_{2} \mathrm{O}_{3} 0.45 \mathrm{wt}\right.$.\%) made the Gr-4 group dissimilar to the previous three groups.

High concentrations of lead ( $\mathrm{PbO} 11.0-22.0 \mathrm{wt} . \%)$, copper ( $\mathrm{CuO} 6.8-11 \mathrm{wt} . \%)$ and iron $\left(\mathrm{Fe}_{2} \mathrm{O}_{3}\right.$ 1.5-1.7 wt.\%) were detected in the orange samples of the Gr-5 group, except in the yellowish sample AR2 $\left(\mathrm{F}_{2} \mathrm{O}_{3} 0.7 \mathrm{wt} . \%\right)$. Furthermore, the amount of antimony and tin were higher than the Gr-4 group, especially in samples AR2 and $\mathrm{AR} 4\left(\mathrm{Sb}_{2} \mathrm{O}_{3} 1.4 \mathrm{wt} . \%, \mathrm{SnO}_{2} 1.1\right.$ and $\mathrm{Sb}_{2} \mathrm{O}_{3} 1.2 \mathrm{wt} . \%, \mathrm{SnO}_{2} 1.2 \mathrm{wt} . \%$, respectively).

\subsection{Identification of Colouring Agents}

\subsection{1. (FEG-SEM)}

In the Gr-1 samples, the copper-rich particles were revealed. In the samples R2, R5 and R6, the copper-rich particles varied from 60 to $200 \mathrm{~nm}$ in size (Figure 12a) and in the samples R3-R4, these were between 100 and $400 \mathrm{~nm}$. Furthermore, the shapes of these particles seemed to change with 
the increase of their dimension. Particles with less than $100 \mathrm{~nm}$ exhibited a spherical shape, while a cubic habitus was observed for particles larger than $100 \mathrm{~nm}$ (Figure 12b). Samples R7-R8 showed both particles with spherical and cubic shape in the range of 60 and $200 \mathrm{~nm}$.
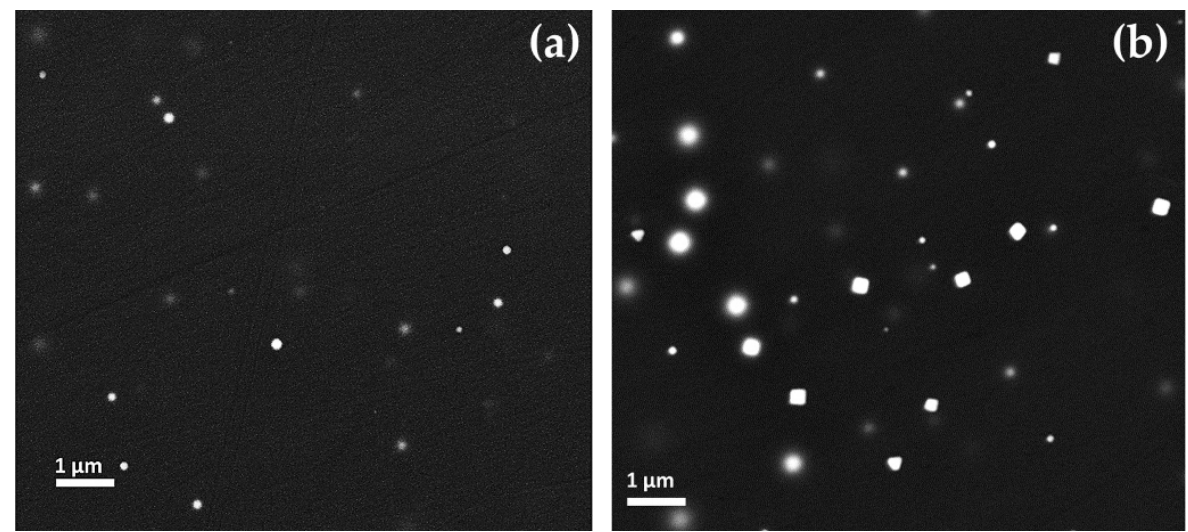

Figure 12. FEG-SEM micrographs of Gr-1 samples: (a) Sample R2, copper spherical nanoparticles; (b) copper spherical and cubic nanoparticles in sample R4.

The heterogeneity of these samples was due to the compresence of opaque red layers with different red hues and the layers appearing dark transparent. In the first case, the lighter red layers were characterized by an elevated number of small copper-rich particles (Figure 13a); on the contrary in the darker red layers, the number of particles decreased and they were enlarged in size (Figure 13b). The transparent dark layers were regions of greenish glass where no particles were observed. No significant chemical compositional differences were revealed between the dark transparent and opaque red bands.
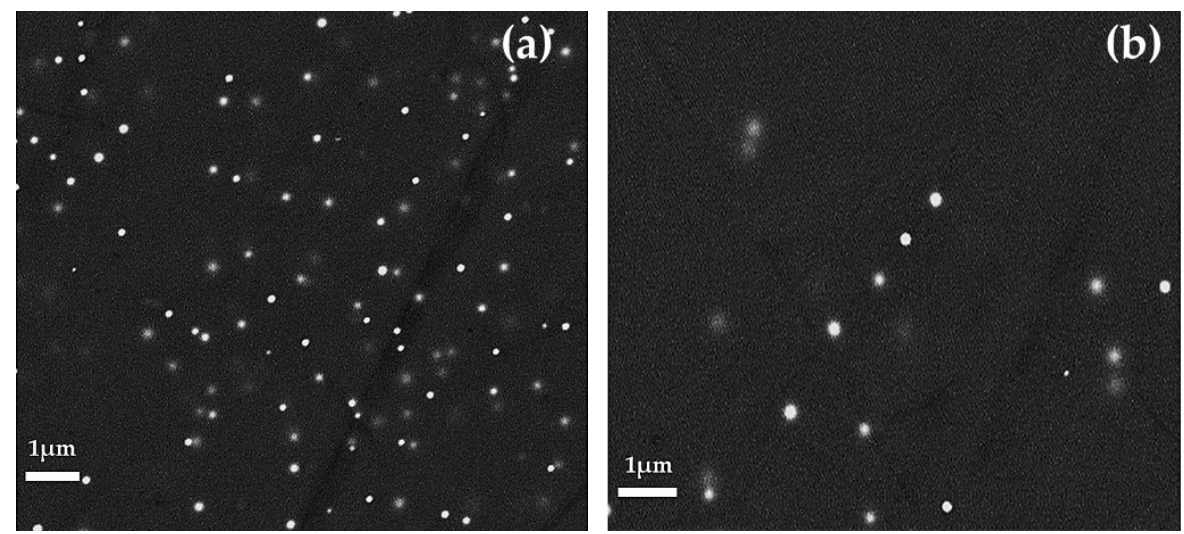

Figure 13. FEG-SEM micrographs of Gr-1 samples. Different red layer with different number and size of particles in sample R31: (a) Orange layer and (b) red layer.

Euhedral copper-rich particles (in hexagonal, triangular and square shaped in cross-section) were revealed in Gr-2 samples (Figure 14a,b). While their dimension increased up to more than $1 \mu \mathrm{m}$, they were present in lower numbers, as compared to the Gr-1 group. Some of these crystals were larger than $10 \mu \mathrm{m}$ and appeared as a white line (Figure 14a encircled with a yellow line), which corresponded to their vertical section or their thickness. 

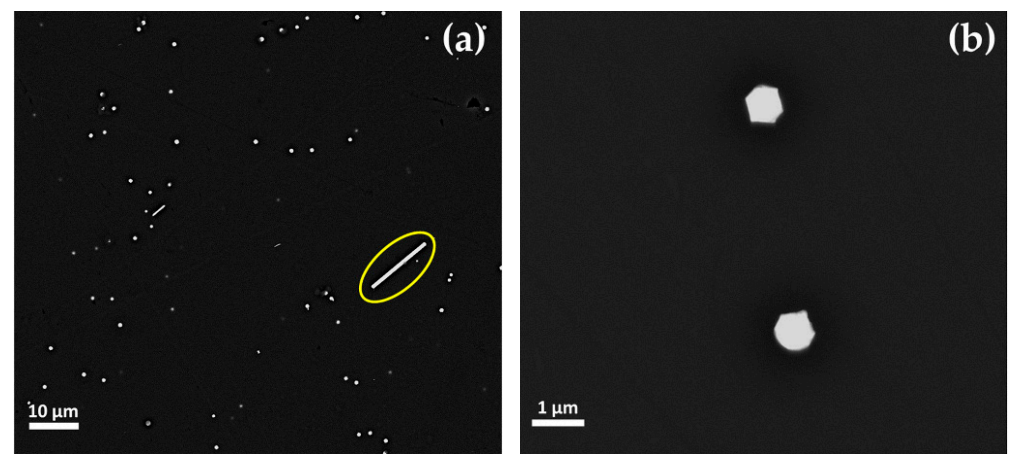

Figure 14. FEG-SEM micrographs of sample R10 (Gr-2 group). (a) Different dimensions of the copper-rich particles-few and large platelet-type (line in cross-section) and abundant but much smaller copper-rich particles; and (b) copper-rich particles at higher magnification.

The dark transparent and the opaque red layers of the samples of Gr-3 group were analysed separately by FEG-SEM. No considerable compositional differences were detected between the two layers; only the red layers were a result of being richer in iron (R1: $5.4 \mathrm{wt} . \%$; R22: $4.5 \mathrm{wt} . \%$ ) than the dark transparent areas (R1: $4.6 \mathrm{wt} . \%$; R22: $3.3 \mathrm{wt} . \%$ ).

A high number of copper-rich particles, in the range of between 50 and $100 \mathrm{~nm}$, were observed in the red layers (Figure 15a,b). Particles rich in copper and sulphur (probably $\mathrm{Cu}_{2} \mathrm{~S}$ ), slightly larger than $1 \mu \mathrm{m}$ in size, were observed constantly in both the red and in the dark transparent layers.
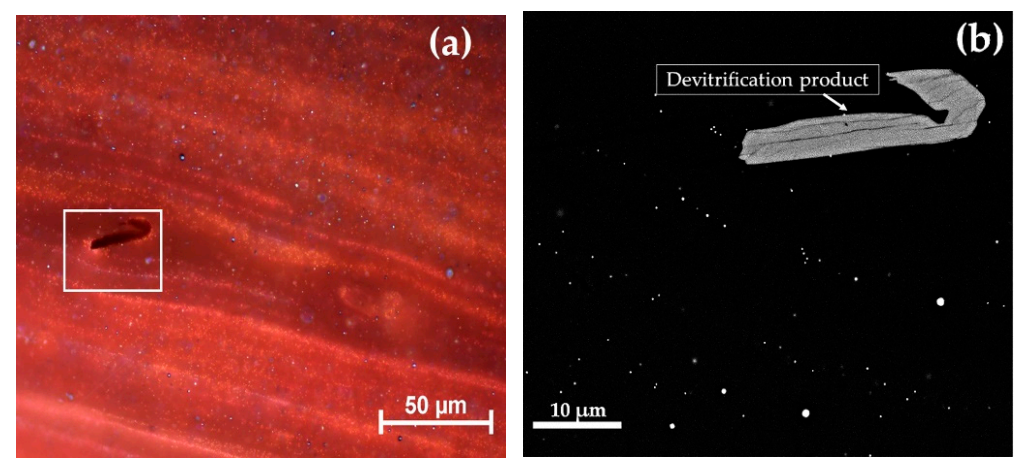

Figure 15. Gr-3 group sample: R22 at optical micrograph (a) and FEG-SEM micrographs of R22 (b).

The samples of the Gr-4 group appeared to be very homogeneous with dendritic-shape particles (Figure 16) rich in copper and oxygen, likely cuprous oxide. These crystals were of different sizes in the four analysed samples reaching micrometric sizes.

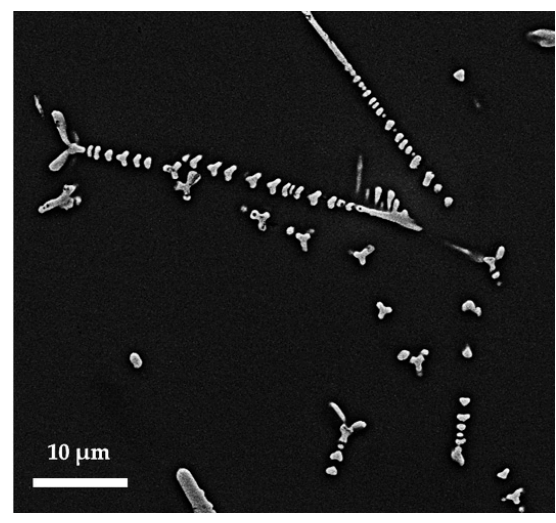

Figure 16. FEG-SEM micrographs cuprite crystal in sample R9 (Gr-4). 
The two hues of this group seemed to be affected by different number and sizes of cuprous oxide particles-few large crystals in the darkest sealing wax (R11-R12) and a high number of small dendritic cuprite crystals in the lightest (R9-R13).

Crystals rich in $\mathrm{Cu}$ and $\mathrm{O}$, likely cuprous oxide, were observed in all orange samples (Gr-5 group). Each orange hue of Gr-5 group was characterized by a distinct abundance and size of the crystals. The yellowish orange samples exhibited a high number of crystalline particles, which had hexagonal or cubic habitus. In sample AR1 (Figure 17a), the crystals varied between 100 and $300 \mathrm{~nm}$, while in sample AR2 (Figure 17b), the number of the particles increased and their sizes were slightly lower (200 nm).
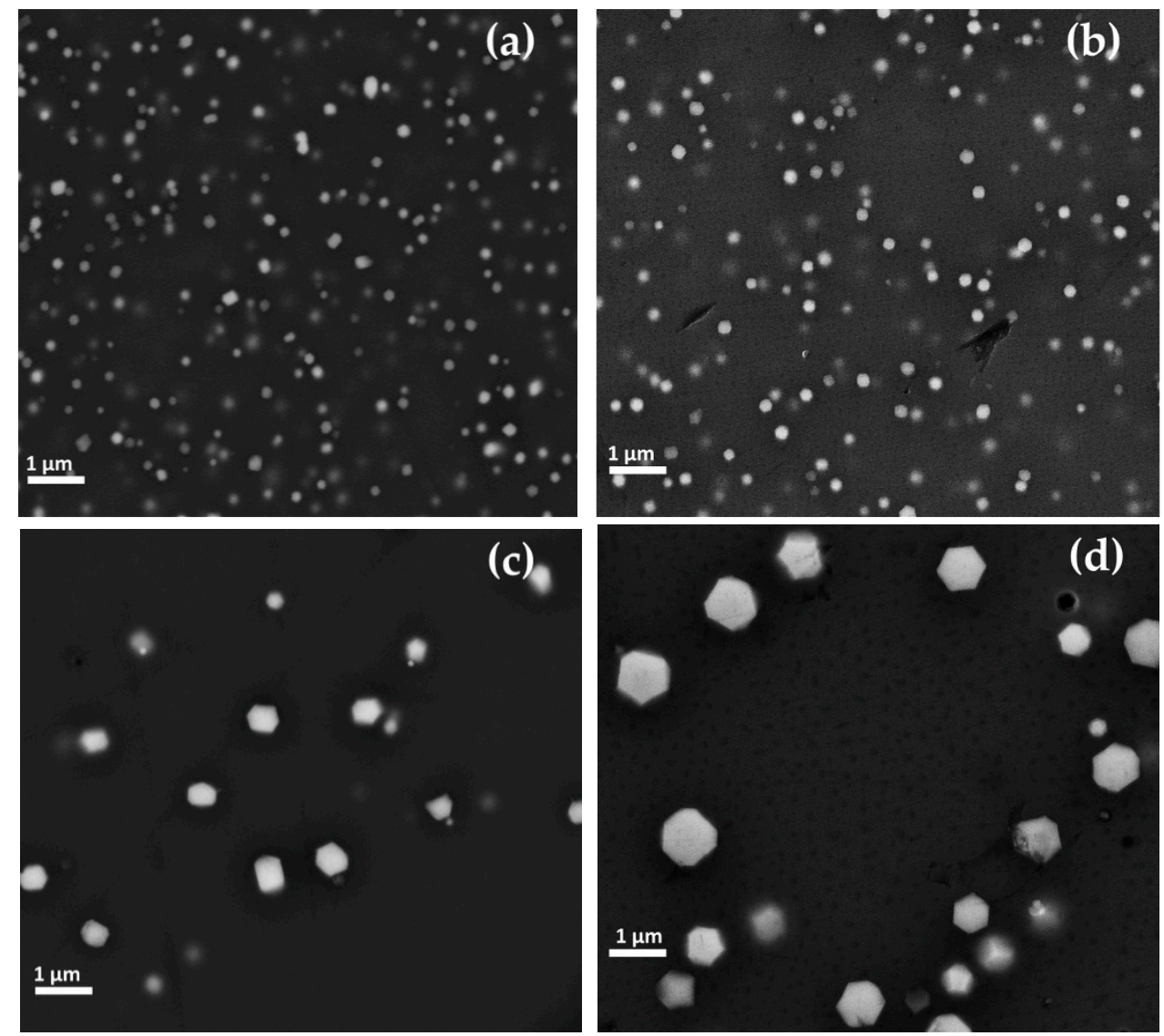

Figure 17. FEG-SEM micrographics of Gr-5 group samples—cuprite crystals observed in sample AR1 (a) and AR2 (b), AR8 (c) and AR4 (d).

In the reddish orange hue, the concentration of crystals seemed to be reduced, while they were enlarged in size. Sample AR8 (Figure 17c) exhibited large copper-rich particles reaching approximately $1 \mu \mathrm{m}$ and showing mainly hexagonal shapes, while in sample AR4 (Figure 17d), the sizes were included in the range of 200 and $800 \mathrm{~nm}$, with hexagonal habitus.

The heterogeneity of the samples composed of red and orange layers (AR1, AR4 and AR8), was investigated carefully using FEG-SEM. No compositional differences were revealed by chemical analyses, on the contrary copper-rich particles showing different sizes and different abundance were observed; a high number of small crystals were detected in the yellow layer, while few large crystals were revealed in the red layer (sometime in dendritic shape) (Figure 18). 

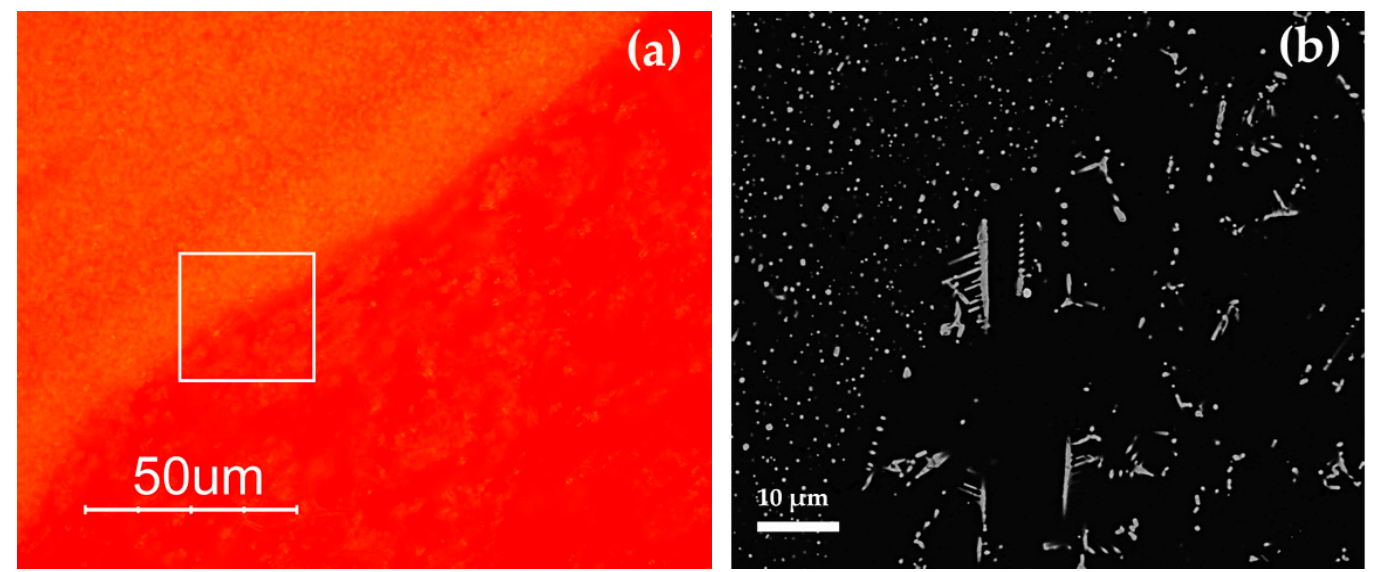

Figure 18. Optical (a) and FEG-SEM micrographs (b) of the red layer and orange layer in sample AR4 (Gr-5).

In order to know how much copper remained in the glassy phase and how much copper precipitated to form the copper-rich particles, mean measurements were performed in the samples of the five groups. Through EDS analyses, two different areas of the samples were investigated-(a) in a large mean area including the glassy phase and nanoparticles, and (b) in a much smaller area embodying only the glassy phase. Results are reported in Table 5. It was observed that the differences of copper contents between the average area and the glassy phases were very low. In the samples coloured by $\mathrm{Cu}^{\circ}$ particles (R16 and R19), the compositional difference was minimal, ranging between 0.2 (Gr-1) or $0.6 \mathrm{wt} . \%$ (Gr-2). In the samples coloured by $\mathrm{Cu}_{2} \mathrm{O}$, these compositional differences were more evident, varying between $3.4 \mathrm{wt} . \%(\mathrm{Gr}-4)$ and $4.3 \mathrm{wt} . \%(\mathrm{Gr}-5)$. This evidence suggests that it is likely that only a low percentage of copper precipitated as $\mathrm{Cu}^{\circ}$ or $\mathrm{Cu}_{2} \mathrm{O}$ [31].

Table 5. Average (crystals + glassy phase) and punctual (glassy phase). EDS analyses performed in the five groups. Two samples coloured by $\mathrm{Cu}^{\circ}$ particles and two samples coloured by $\mathrm{Cu}_{2} \mathrm{O}$ particles. S.D.-standard deviation; five measurements were performed (at least) for the investigated area.

\begin{tabular}{|c|c|c|c|c|c|c|c|c|}
\hline \multirow{2}{*}{$\begin{array}{l}\text { Oxide } \\
\text { Group }\end{array}$} & Average & Glassy Phase & Average & Glassy Phase & Average & Glassy Phase & Average & Glassy Phase \\
\hline & \multicolumn{2}{|c|}{ R16 (Gr-1) } & \multicolumn{2}{|c|}{ R19 (Gr-2) } & \multicolumn{2}{|c|}{ R12 (Gr-4) } & \multicolumn{2}{|c|}{ AR4 (Gr-5) } \\
\hline $\mathrm{Al}_{2} \mathrm{O}_{3}$ & 1.4 & 1.4 & 2.1 & 2.1 & 1.5 & 1.6 & 1.9 & 1.7 \\
\hline S.D. & 0.09 & 0.06 & 0.05 & 0.05 & 0.06 & 0.03 & 0.12 & 0.07 \\
\hline $\mathrm{Na}_{2} \mathrm{O}$ & 13.6 & 13.6 & 17.0 & 17.0 & 10.7 & 10.8 & 13.0 & 14.3 \\
\hline S.D & 0.24 & 0.12 & 0.06 & 0.07 & 0.12 & 0.05 & 0.34 & 0.49 \\
\hline $\mathrm{K}_{2} \mathrm{O}$ & 3.4 & 3.4 & 0.73 & 0.72 & 0.37 & 0.33 & 1.2 & 1.1 \\
\hline S.D & 0.09 & 0.03 & 0.02 & 0.02 & 0.04 & 0.03 & 0.07 & 0.02 \\
\hline $\mathbf{P}_{2} \mathrm{O}_{5}$ & 1.0 & 1.1 & 0.13 & 0.20 & 0.06 & 0.10 & 0.40 & 0.32 \\
\hline S.D & 0.08 & 0.07 & 0.06 & 0.05 & 0.05 & 0.05 & 0.04 & 0.02 \\
\hline $\mathrm{Fe}_{2} \mathrm{O}_{3}$ & 1.2 & 1.2 & 5.0 & 4.9 & 0.63 & 0.67 & 1.5 & 1.7 \\
\hline S.D & 0.09 & 0.11 & 0.08 & 0.09 & 0.08 & 0.10 & 0.10 & 0.01 \\
\hline $\mathrm{MnO}$ & 0.30 & 0.33 & 0.40 & 0.40 & 0.17 & 0.30 & 0.27 & 0.35 \\
\hline S.D & 0.08 & 0.12 & 0.07 & 0.07 & 0.10 & 0.09 & 0.08 & 0.07 \\
\hline $\mathrm{CuO}$ & 2.8 & 2.6 & 3.3 & 2.8 & 9.6 & 6.2 & 11.0 & 6.7 \\
\hline S.D & 0.32 & 0.10 & 0.27 & 0.13 & 0.64 & 0.19 & 0.39 & 0.35 \\
\hline $\mathrm{PbO}$ & 0.67 & 0.82 & 1.1 & 1.2 & 28.0 & 29.2 & 7.8 & 8.5 \\
\hline S.D & 0.09 & 0.07 & 0.07 & 0.06 & 0.64 & 0.23 & 0.39 & 0.12 \\
\hline $\mathrm{SnO}_{2}$ & 0.51 & 0.47 & 0.46 & 0.46 & 0.24 & 0.14 & 1.2 & 1.2 \\
\hline S.D & 0.13 & 0.17 & 0.09 & 0.11 & 0.09 & 0.09 & 0.07 & 0.08 \\
\hline
\end{tabular}

\subsubsection{Raman}

Through the Raman spectroscopy, it was not possible to detect the copper-rich particles in the samples of Gr-1, Gr-2 and Gr-3 groups. Metallic copper is not Raman active and no peaks were observed [72,73]. Furthermore, most of the red samples (Gr-1 group) showed high fluorescence, 
which did not convey any information about the colouring agent. However, the typical cuprite peaks were not revealed, which could exclude its presence in these groups. The Raman spectra obtained (Figure 19a,b) showed the typical features of silicate glass, composed of the two main regions attributable to the bending modes (between $400-500 \mathrm{~cm}^{-1}$ ) and the stretching modes $\left(900-1000 \mathrm{~cm}^{-1}\right.$ ) of Si-O [72-74].
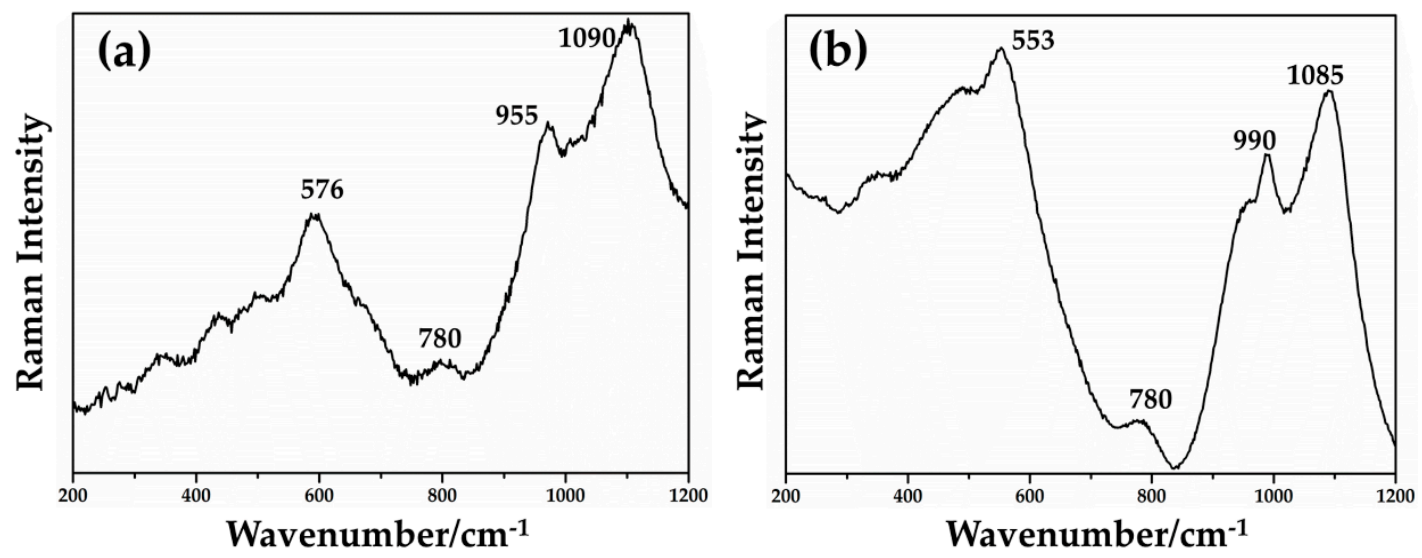

Figure 19. Raman spectra of the samples in Gr-1 group (a) and in Gr-2 group (b).

By focusing red $\mu$ Raman laser (532 nm) on the dendritic crystals in samples from the Gr- 4 and Gr-5 groups, the spectra characterized by an intense peak at $218 \mathrm{~cm}^{-1}$ were observed (Figure 20a,b). Other weak bands at 416 and $630 \mathrm{~cm}^{-1}$ were obtained for the Gr-4 samples (Figure 20a), while two weak peaks at 409 and $624 \mathrm{~cm}^{-1}$ were visible in the spectra of orange samples (Figure 20b). These features were in good agreement with the Raman spectra of cuprite $\left(\mathrm{Cu}_{2} \mathrm{O}\right)$ present in the literature, belonging to the Pn3m space group [75]. The peaks at 140 and $160 \mathrm{~cm}^{-1}$, and $630 \mathrm{~cm}^{-1}$ were due to a lattice mode, while the peaks at $215-218 \mathrm{~cm}^{-1}$ and between 400 and $490 \mathrm{~cm}^{-1}$ were attributed to multiphonon Raman scattering [76]. The peak at 142 and $145 \mathrm{~cm}^{-1}$ could be related to the crystal lattice vibration of $\mathrm{Pb}-\mathrm{O}[75]$.
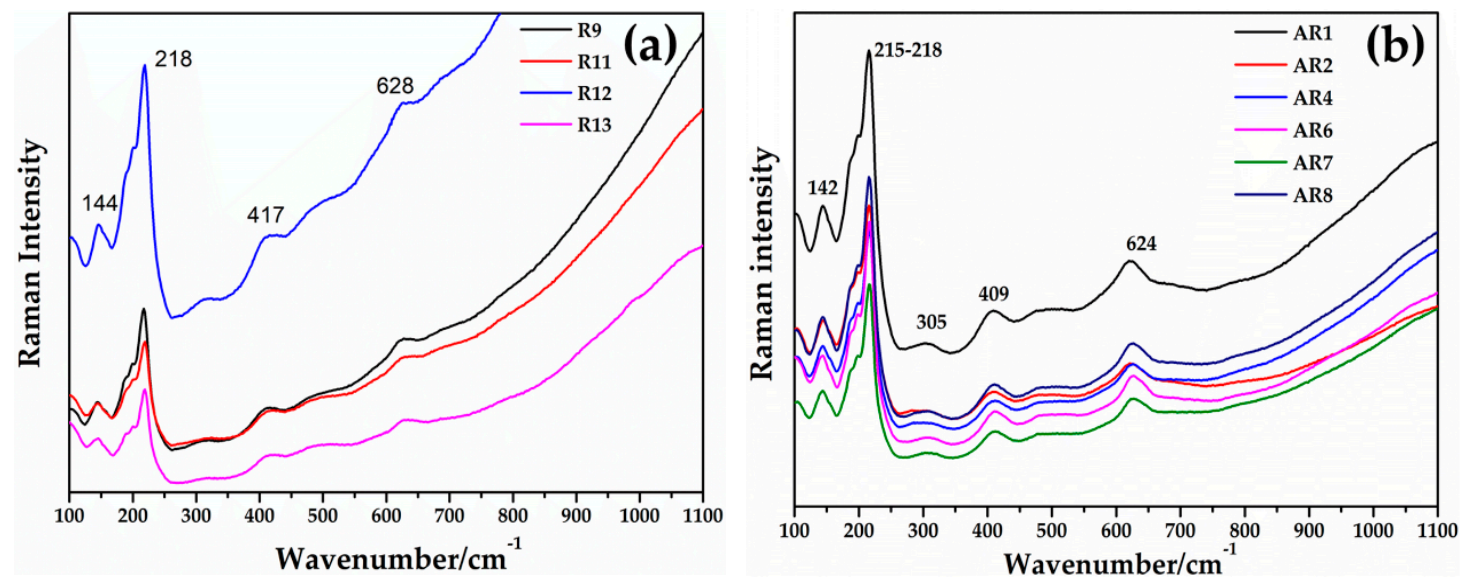

Figure 20. Raman spectrum of cuprite $\left(\mathrm{Cu}_{2} \mathrm{O}\right)$ detected in $\mathrm{Gr}-4(\mathbf{a})$ and $\mathrm{Gr}-5(\mathbf{b})$ groups.

\subsubsection{XRD}

X-ray diffraction performed on representative samples for Gr-1 (R2-R4-R5), Gr-2 (R10) groups showed a broad peak of between $20^{\circ}$ and $30^{\circ}$ (2Theta), typical of vitreous material, and two weak peaks at $\mathrm{d}=2.09, \mathrm{~d}=1.81$, which were assigned to metallic copper with cubic symmetry (Figure 21). The different intensity of the peaks observed between the two groups was probably due to the 
differences in size and concentration of crystals, indicating that the sample contained R10 particles of metallic copper larger than the samples of Gr-1 group.
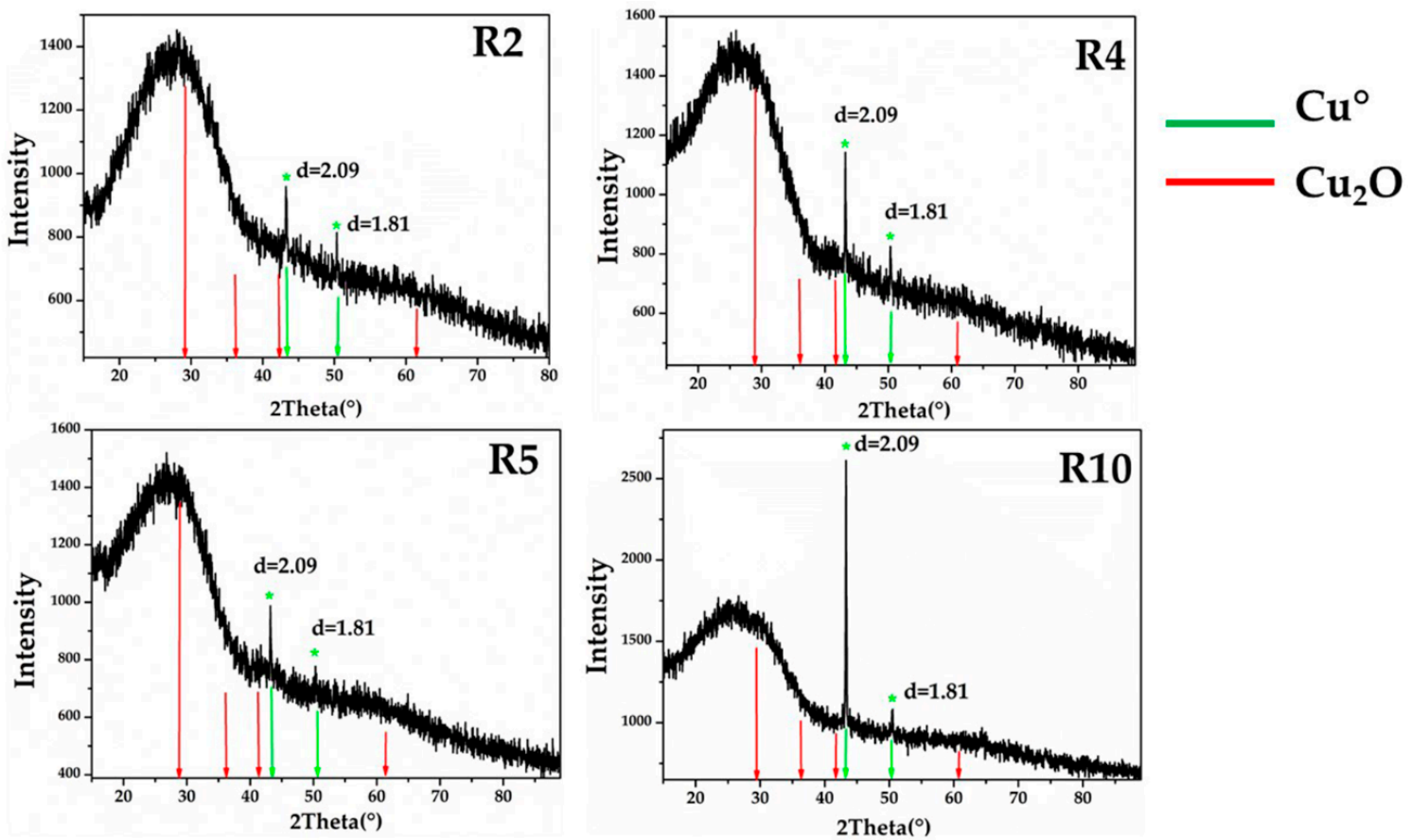

Figure 21. X-ray diffraction on the samples of Gr-1 (R2-R4-R5) and Gr-2 (R10), showing the typical peaks of metallic copper. No cuprite crystals were detected.

Due to the small size of the Gr-3 samples, these were not analysed by X-ray diffraction.

XRD analyses (Figure 22) in the Gr-5 groups, showed intense peaks at $d=3.01, d=2.46, d=2.13$, $\mathrm{d}=1.51$ and $\mathrm{d}=1.28$, which were characteristic of cuprite crystals. No other crystalline phases were detected in the orange samples by mean of XRD analyses. Only micro-samples of the Gr-4 group were available for the XRD analyses, which were too small to obtain good and precise results.
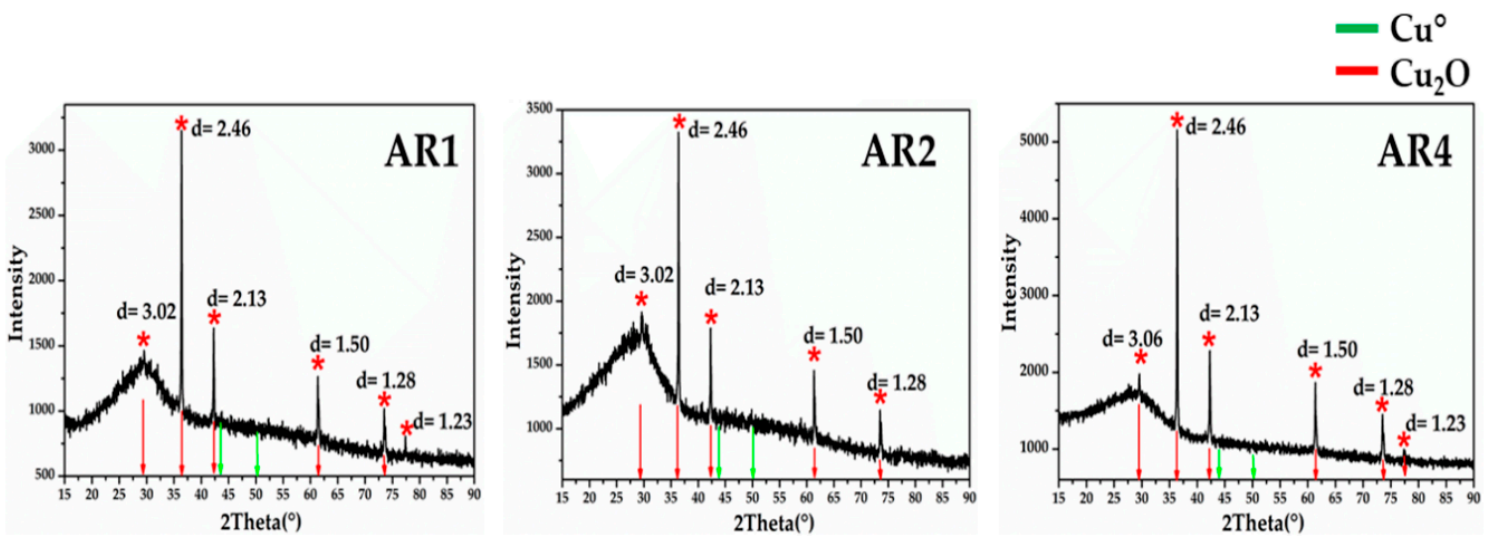

Figure 22. X-ray diffraction for the three orange samples of Gr-5 group. The diffractograms showed the typical peaks of cuprite cubic crystals. No metallic copper crystals were detected.

\subsubsection{Other Crystalline Phases}

Several crystalline phases, different from the colouring particles, were identified by SEM-EDS and Raman spectroscopy in several samples. The crystalline phases, the inclusions, and devitrification products, are shown in Table 6, in order to have a general view of the results obtained in the five hues. 
Table 6. Colouring, metallic and devitrification particles investigated by FEG-SEM, Raman spectroscopy and X-ray diffraction. $\mathrm{Cu}^{\circ}$ : metallic copper; $\mathrm{Cu}{ }_{2} \mathrm{O}$ : $\mathrm{Cuprite}$ W: wollastonite $\left(\mathrm{CaSiO}_{2}\right)$; Dt: Devitrite $\left(\mathrm{Na}_{2} \mathrm{O} \cdot 3 \mathrm{CaO} \cdot 6 \mathrm{SiO}_{2}\right)$, Dp: diopside $\left(\mathrm{CaO} \cdot \mathrm{MgO} \cdot 2 \mathrm{SiO}_{2}\right)$. Pol.: polyphase (Al-Si-Na-Fe-Ca); C: Chalcocite $\left(\mathrm{Cu}{ }_{2} \mathrm{~S}\right)$; $\mathrm{CP}$ : calcium phosphate; $\mathrm{CA}$ : calcium antimonate $\left(\mathrm{Ca}_{2} \mathrm{Sb}_{2} \mathrm{O}_{7}\right)$; Mgn: magnetite $\left(\mathrm{Fe}_{3} \mathrm{O}_{4}\right)$; Hem. Hematite $\left(\mathrm{Fe}_{2} \mathrm{O}_{3}\right)$; Inc. A: inclusions composed by Cu-Ag-Sb; Inc. B: PbS-Cu $\mathrm{S}_{2}$; and Inc.C: inclusions rich in $\mathrm{Fe}_{2} \mathrm{O}_{3}, \mathrm{SiO}_{2}, \mathrm{Al}_{2} \mathrm{O}_{3}$ and $\mathrm{TiO}_{2}$.

\begin{tabular}{|c|c|c|c|c|c|c|c|c|c|}
\hline \multirow{2}{*}{ Group } & \multirow{2}{*}{ Sub-Group } & \multirow{2}{*}{ Colour-Hues } & \multirow[b]{2}{*}{ Colouring $(\mu \mathrm{m})$} & \multicolumn{2}{|c|}{ FEG-SEM (Particles) } & \multirow[b]{2}{*}{ Metallic $(\mu \mathrm{m})$} & \multicolumn{2}{|c|}{ Raman (Particles) } & \multirow{2}{*}{ XRD } \\
\hline & & & & Devitrification & Others & & Colouring & Others & \\
\hline Gr-1 & - & Brick red & $\mathrm{Cu}^{\circ}$ 0.04-0.7 & W; Dt; Dp. & $\begin{array}{l}\text { Pol. (R3-R14); } \\
\text { CP (R6-R26); }\end{array}$ & $\begin{array}{l}\text { Mgm (R6-R8);C (R26); } \\
\text { Inc.A (R16); Inc.B (R8) }\end{array}$ & - & $\begin{array}{l}\text { Inc.C } \\
\text { (R26) }\end{array}$ & $\mathrm{Cu}^{\circ}$ \\
\hline Gr-2 & - & $\begin{array}{l}\text { Reddish } \\
\text { brown }\end{array}$ & $\mathrm{Cu}^{\circ}>1$ & - & $\begin{array}{l}\text { Inc.C (R10); } \\
\text { Pol. (R17) }\end{array}$ & C (R17) & - & - & $\mathrm{Cu}^{\circ}$ \\
\hline \multirow{3}{*}{ Gr-3 } & Average & Dark red & & & & \multirow{3}{*}{$\begin{array}{c}C(0.1) ; \text { hem. } \\
\text { C (0.1) }\end{array}$} & - & & - \\
\hline & Gr-3cBK & Black layer & & W; Dt. & - & & - & & - \\
\hline & Gr-3cR & Red layer & $\mathrm{Cu}^{\circ} 0.02-0.1$ & W; Dt. & - & & - & & - \\
\hline Gr-4 & - & Sealing wax & & & & $\mathrm{Cu}^{\circ}(\mathrm{R} 9-\mathrm{R} 11)$ & $\mathrm{Cu}_{2} \mathrm{O}$ & & \\
\hline \multirow[t]{2}{*}{ Gr-5 } & Gr-5dOr & $\begin{array}{l}\text { Yellowish } \\
\text { orange }\end{array}$ & $\mathrm{Cu}_{2} \mathrm{O}(0.1-0.3)$ & W; Dt (AR1) & CA & & $\mathrm{Cu}_{2} \mathrm{O}$ & $\mathrm{CA}(\mathrm{AR} 2)$ & $\mathrm{Cu}_{2} \mathrm{O}$ \\
\hline & Gr-5dR & $\begin{array}{l}\text { Reddish } \\
\text { orange }\end{array}$ & AR4: $\mathrm{Cu}_{2} \mathrm{O}$ 0.3-1 & W; Dt (AR4) & & & $\mathrm{Cu}_{2} \mathrm{O}$ & & $\mathrm{Cu}_{2} \mathrm{O}$ \\
\hline
\end{tabular}


Euhedral crystals rich in Ca-Si or Na-Ca-Si, classical devitrification products [77], were detected in several samples of the Gr-1, Gr-3 and Gr-5 groups. No devitrification products were revealed in the samples of the Gr-2 and Gr-4 groups. In the samples with higher concentrations of phosphorus (R6-R26), crystalline phases rich in calcium and phosphorus (probably calcium phosphate) were identified. Furthermore, inclusions with compositions comparable to magnetite $\left(\mathrm{Fe}_{3} \mathrm{O}_{4}\right)$ and chalcocite $\left(\mathrm{Cu}_{2} \mathrm{~S}\right)$ were observed in samples of the Gr-1, Gr-2 and Gr-3 groups. In sample R16, a spherical inclusion rich in copper, silver and sulphur was identified. This inclusion was surrounded by particles measuring 10 micron in size, rich in silver, copper and antimony (Figure 23a). Inclusions rich in Si-Al-Fe-K-Na (probable a clay material) were observed in sample R10 (Figure 23b). In the red-banded samples (Gr-3), spherical particles composed of copper and sulphur were encountered in both layers (Figure 23c), while in sample R1 (in the dark transparent layer), a large inclusion of hematite $\left(\mathrm{Fe}_{2} \mathrm{O}_{3}\right)$ was detected together with a devitrification product (wollastonite).
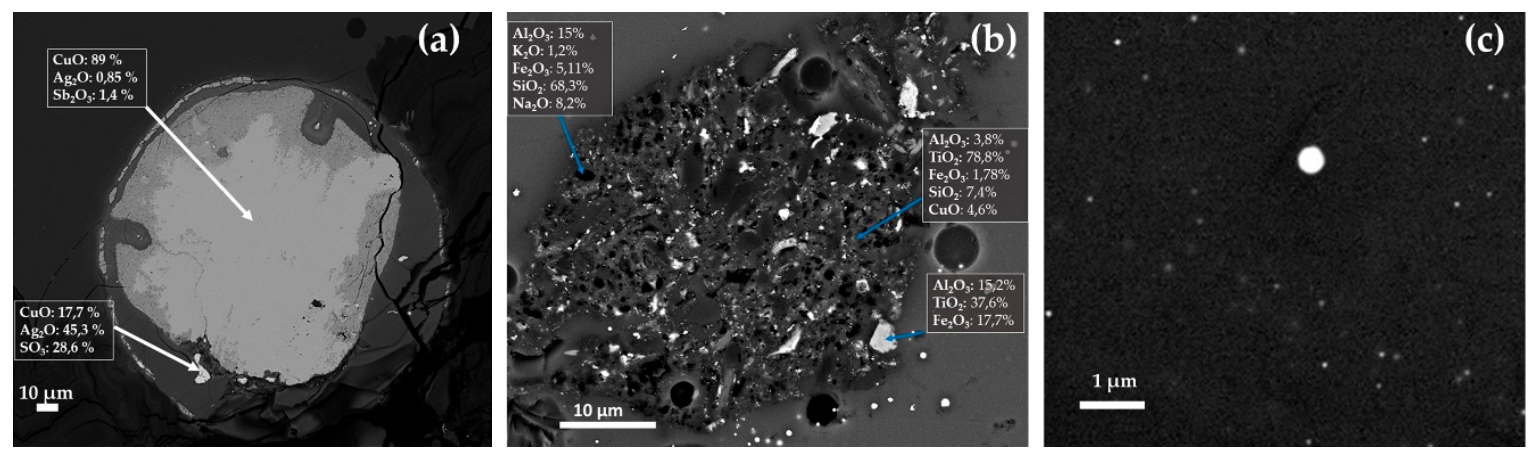

Figure 23. FEG-SEM micrographs of R16, R10 and R1 samples. Inclusion rich in Ag in R16 (a); probable clay inclusion in sample R10 (b); and spherical particles of $\mathrm{Cu}_{2} \mathrm{~S}$ in sample R1 (c).

Through SEM-EDS, spread of aggregates of euhedral crystals throughout different areas of the sample AR2 were detected, showing a high concentration of calcium, antimony, tin, lead and low amounts of iron (Figure 24a). These crystalline phases were identified as calcium antimonite through the Raman spectroscopy (Figure 24b).
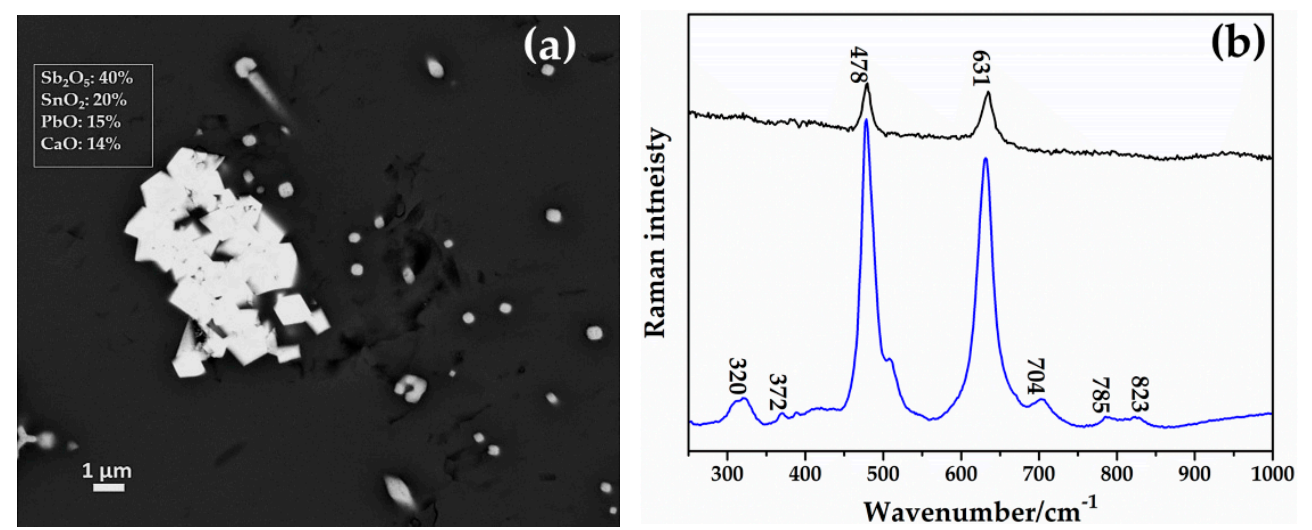

Figure 24. (a) FEG-SEM micrograph showing aggregates of $\mathrm{CaSb}_{2} \mathrm{O}_{7}$ in sample AR2. (b) Raman spectra of two $\mathrm{CaSb}_{2} \mathrm{O}_{7}$ (calcium antimonate) detected in the sample AR2.

The sharp peaks situated at 478 and $631 \mathrm{~cm}^{-1}$ were the typical fingerprint of orthorhombic calcium antimonate $\left(\mathrm{Ca}_{2} \mathrm{Sb}_{2} \mathrm{O}_{7}\right)[75,78]$; the weak peaks at 320 and $372 \mathrm{~cm}^{-1}$ were due to the bending mode of the $\mathrm{O}-\mathrm{Sb}-\mathrm{O}$, while the other weak peaks at 785 and $823 \mathrm{~cm}^{-1}$ were combinations of overtone $[75,78]$. 


\section{Discussion}

The copper-red glass sectilia studied in the Gorga collection were divided in two distinct glassmaking technologies. The first technology included the samples of Gr-1, Gr-2 and Gr-3 groups, which were coloured by metallic copper $\left(\mathrm{Cu}^{\circ}\right)$. It was observed that the number and size of metallic copper particles were distinguished by three different hues (Figure 25). Metallic copper between 50-500 nm coloured the brick red samples (Gr-1), while $\mathrm{Cu}^{\circ}$ larger than $1 \mu \mathrm{m}$ were detected in the reddish brown samples (Gr-2), which in some cases reached $50 \mu \mathrm{m}$ in sizes. The red-banded samples (Gr-3) were coloured (in the red layers) by $\mathrm{Cu}^{\circ}$ nanoparticles between $50-100 \mathrm{~nm}$.

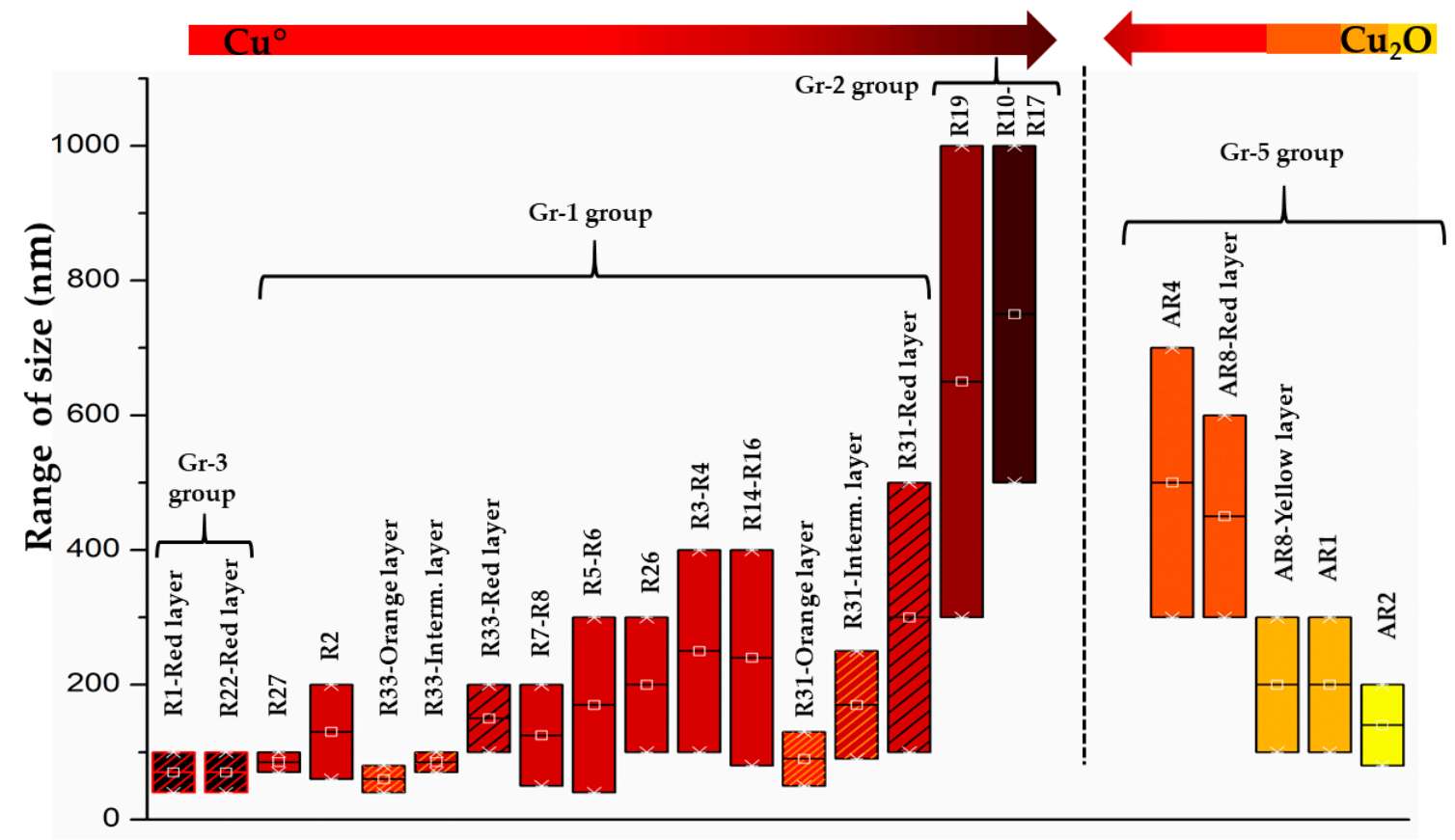

Figure 25. The colour changes with the increase of the colouring agent dimensions $\left(\mathrm{Cu}^{\circ}\right.$ on the right; $\mathrm{Cu}_{2} \mathrm{O}$ on the left).

The second technology was represented by Gr-4 and Gr-5 groups, which were coloured by cuprite crystals. The process required to produce cuprite crystals, which included chemical composition and heat treatments, was extremely different from the technology of metallic copper. Dendritic cuprite crystals were tens of micrometre in magnitude in the sealing wax red glass (Gr-4), while in the orange samples, the crystals were usually smaller than $800 \mathrm{~nm}$ and mainly present in cubic and hexagonal forms (Gr-5). Furthermore, the yellowish orange hues were characterized by high numbers of small cuprite crystals $(<300 \mathrm{~nm})$, while on the contrary the number of particles were slightly diminished in the red orange samples, promoting larger cuprite hexagonal crystals between 400-800 nm in size.

In both technologies, the comparison between the average chemical composition (glassy phase + crystals) and the punctual EDS analyses on the glassy phase among the copper-rich particles, highlighted only small differences in the concentration of copper. It suggests that only a small percentage of copper precipitates to form $\mathrm{Cu}^{\circ}$ or $\mathrm{Cu}_{2} \mathrm{O}$, while the majority remain in the form of $\mathrm{Cu}^{+}$, or $\mathrm{Cu}^{2+}$ ion. It is possible to observe that, in general, the amount of $\mathrm{Cu}^{+}$that precipitated to form cuprite crystals was higher than that of $\mathrm{Cu}^{\circ}$, highlighting the strong colouring power of the metallic copper. For instance, the modern copper red glass, coloured by $\mathrm{Cu}^{\circ}$, is usually manufactured with only $0.1 \mathrm{wt}$.\% of copper and the addition of a strong reducing agent, such as tin or coke.

The technological aspects involved in the manufacturing of each group is discussed in the following paragraphs. 


\section{1. $C u^{\circ}$ Colouring Technique}

The three groups showed the use of two different types of base glass-natron base glass in the Gr-2 and Gr-3 groups and a soda plant ash base glass in the Gr-1 group.

The high concentrations of $\mathrm{K}_{2} \mathrm{O}, \mathrm{MgO}$ and $\mathrm{CaO}$ with low content of $\mathrm{Na}_{2} \mathrm{O}$ suggest the use of soda plant ash base glass, rather than the addition of potash ash to a natron base glass. $\mathrm{P}_{2} \mathrm{O}_{5}$ content was higher than the usual soda plant ash base glass but this could be due to two factors-(a) the high variable composition of the plants, which depends on the nature of the substrate and how the specific elements are synthesized in their tissue [79] and (b) the addition of fuel ash to a soda plant ash base glass.

In the opaque red glass, the use of a soda plant ash base glass, seemed to correspond to a well-mastered recipe, especially diffused in the early period of the Roman age (1st-4th century AD), as well as several studies that highlighted this [36,41-43,45,47]. This recipe could be engineered to solve the most crucial aspect of the opaque red glass production, the correct redox oxidation state in the melt. As mentioned in the introduction, the addition of an internal reductant is fundamental to reducing copper in its elemental state $\left(\mathrm{Cu}^{\circ}\right)$. In our case, iron is the reducing agent, confirmed by its moderate concentration in the Gr-1 group, which interacts with copper, according to the redox equation (Equation (2)).

$$
\mathrm{Cu}^{+}+\mathrm{Fe}^{2+} \Leftrightarrow \mathrm{Cu}^{\circ}+\mathrm{Fe}^{3+}
$$

The proportion of $\mathrm{Cu}^{+} / \mathrm{Cu}^{\circ}$ and $\mathrm{Fe}^{2+} / \mathrm{Fe}^{3+}$ depends on the temperature, but during cooling, the equilibrium (Equation (2)) was displaced toward the right, inducing the formation of $\mathrm{Cu}^{\circ}$ and $\mathrm{Fe}^{3+}[11,18]$.

In the case of our red glass sectilia, the use of partially burned soda ashes, containing carbonaceous compounds, produced a reduced base glass, which needs less iron for the formation of $\mathrm{Cu}^{\circ}$ nanoparticles $[41,80]$. This technical benefit could bring the Roman glassmakers to prefer the use of soda plant ash as a fluxing agent, in order to achieve a vivid or light red hue. In fact, the higher the iron content, the darker or more brownish is the red hue [16], as was clear in sample R31, which showed a higher concentration of iron than the other samples of Gr-1 group and its colour moved slightly toward reddish brown hue. It was remarkable that distinguishing brick red glass (Gr-1) from the sealing wax (Gr-4) by the naked eye was a difficult task (Figure 26). It underlined that Roman glassmakers were able to obtain a colour very close to the sealing wax by using $\mathrm{Cu}^{\circ}$. Additionally, the colourimetric measurements showed only few differences in the chromatic coordinate, making them very similar.

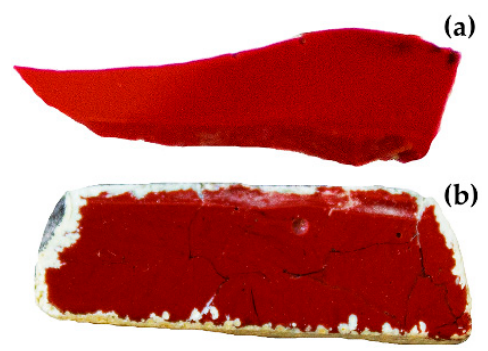

Figure 26. Comparison of two fragments of copper red glass—sealing wax (a) and brick red (b).

The heterogeneity, which microscopically characterized these samples of the Gr-1 group, was due to the presence of dark transparent layers in which no particles were detected, and because layers with different ratios of number and size of $\mathrm{Cu}^{\circ}$ were formed. Identifying the cause that lead to this heterogeneity was complex and it was probable that several factors concerning the melting condition or how the molten glass was cooled, play a crucial role. No significant compositional differences were detected through the chemical analyses. Therefore, it is probable that the glass was not in the correct oxidation state to promote the precipitation of the $\mathrm{Cu}^{\circ}$ particles. Hence, it is likely the proper redox conditions were not achieved in the dark transparent layers. It could be due to the stirring of the 
melt. This operation, for instance, is often mentioned in the Venetian recipe manuscripts, to avoid the formation of dark transparent layers. This procedure helps to mix the more oxidized upper layer of the molten glass (green transparent) with the inner and more reduced part of the melt (red opaque).

This heterogeneity was almost absent in the samples of the Gr-2 group. It could be due to the higher concentration of iron and copper, which stabilized the glass redox environment through a buffering effect. As observed above, the Gr-2 group samples had lower numbers but larger crystals than the red brick samples (Gr-1). This was the result of a higher concentration of copper and of a specific heat treatment.

The high concentration of copper aided the aggregation of the $\mathrm{Cu}^{\circ}$ atoms in large crystals, while the presence of high iron content hampered the formation of cuprous ions [16]. When copper-containing glass was rapidly cooled, metallic copper crystals were chilled in sub-micrometric sizes, caused by the increase of viscosity that prevented the crystal growth, creating an opaque red glass [2,16,81]. On the contrary, crystal growth was favoured when the molten glass was maintained at a temperature that favoured a low viscosity, for a prolonged period and it was slowly cooled. As result, the copper-containing glass would be brown, or in an extreme case, crystals visible to the naked-eye would form [16,81]. This process is driven by Ostwald ripening, which favours the growth of thermodynamically stable particles of a specific size, while the smaller particles dissolve in the glass matrix [82]. Since this technology is temperature and time-dependent, through specific heat treatment, it is possible to control the growth of a few large particles or the high amount of small crystals.

These samples seemed to prove that the Roman glassmakers knew these principles. Likely in an empirical way, however, they foresaw the technological production of aventurine glass, first produced in high amounts by the Venetian glassmakers at the end of the 16th century AD. Aventurine glass was an extreme consequence of a long and slow cooling phase (some Venetian recipes said that it took one week), through which large crystals gave off a clear sparkling effect [83]. The chemical analyses confirmed that the samples of the Gr-2 group were typical Roman natron glass [32,33]; however, the concentrations of copper and iron were very close to those detected in the Venetian aventurine [83].

The samples of the Gr-3 group present red bands in a dark transparent glass. The chemical analyses did not highlight any compositional differences. A redox difference could be suspected to originate from the disproportion of iron (R1: 4.5 wt.\%; R22: 3.9 wt.\%) and copper (R1: 0.27 wt.\%; R22: 0.31 wt.\%). The $\mathrm{Cu}_{2} \mathrm{~S}$ particles (frequently detected in both layers) were the result of a first crystallization, in which the two elements reacted below the melting temperatures. Once the sulphur available to react was consumed, a second crystallization occurred, leading to the formation of metallic copper nanoparticles.

Although iron was abundantly used in the three groups and in general in the production of opaque red glass, it is still unknown what acted as the iron-bearing material. Inclusions comparable with the chemical composition of magnetite and hematite were detected by the FEG-SEM analyses. The use of only iron-rich mineral (such as magnetite) is unlikely because it presents both oxidation states of iron, which makes it a weak reducing agent. Hematite could be ruled out due to its oxidizing action. On the contrary, the use of hammer scale from the beating of incandescent iron could be an alternative hypothesis. Previous studies on Roman black glass from the 2nd century AD observed that iron flakes were used as a colouring agent. This metallurgical by-product could contain wustite $(\mathrm{FeO})$, magnetite and metallic iron, supplying enough reducing agents; furthermore, this is easy to reduce into powder [84-86]. Additionally, this is commonly indicated in the Venetian manuscripts. Hence, the presence of hematite or magnetite could be the relicts of the iron bearing material used as reducing agent.

Beyond the iron, no other reducing agents seem to have been used. The concentrations of tin and antimony were probably not enough to bring any technical benefits. Hence, they probably entered as impurity of metallurgical by products, or as contaminants of glass cullet. The levels of lead oxide were very low. Although, it was usually supposed that lead at a concentration below $5 \mathrm{wt}$ \% did not generate any technical advantage for the manufacturing of the red colour [13], it was not excluded 
that low contents of lead could decrease the viscosity of the melt, facilitating the crystal growth [77]. The inclusion detected in samples R16, composed of silver-copper-antimony, could indicate the use of litharge or slags obtained from a silver-refining process, such as a lead oxide source, as reported by Freestone [13]. Nevertheless, chemical analyses involving the detection of trace elements were necessary to confirm this argument.

Several devitrification products, detected in the three groups, indicated that the molten glass was not rapidly poured but was probably laid at temperatures slightly below the liquidus temperatures, in order to facilitate the precipitation of $\mathrm{Cu}^{\circ}$ particles.

\section{2. $\mathrm{Cu}_{2} \mathrm{O}$ Colouring Technique}

The base glass used in this colouring technique was a lead-soda-lime-silica glass. The differences in the alumina and silica contents could be indicative that different sands were employed for the manufacturing of sealing wax and orange samples. It was likely that, a careful selection of the different types of sand or pure silica pebbles for the sealing wax were used. Conversely, the sand of orange glass would be richer in alumina, $\mathrm{K}_{2} \mathrm{O}$ and $\mathrm{MgO}$, suggesting high concentrations of feldspar and dolomitic minerals, in all likelihood.

Contrary to the $\mathrm{Cu}^{\circ}$ colouring technique, the production of cuprite crystals required high concentration of copper and lead oxide. Strong reducing conditions should be avoided in order to prevent the precipitation of $\mathrm{Cu}^{\circ}$ and metallic lead $\left(\mathrm{Pb}^{\circ}\right)$. Since $\mathrm{Cu}^{+}$was more soluble than $\mathrm{Cu}^{\circ}$, high percentages of copper $\left(\mathrm{Cu}^{+}\right)$should be used for the formation of cuprite crystals. Lead oxide plays a key role in this technology because-(a) it decreases the working temperature, reducing the viscosity and gives enough time for the copper ions to aggregate in dendritic shape and grow; (b) it shifts the $\mathrm{Cu}^{2+} / \mathrm{Cu}^{+}$towards $\mathrm{Cu}_{2} \mathrm{O}[11,18,19]$.

Although modern laboratory reproduction obtained opaque red and orange glass only through management of the heat treatment [17], Roman glassmakers would control the colour with the manipulation of the chemical composition of the glass.

The concentration of lead oxide was different in the two groups (Gr-4 and Gr-5), which could be related to the control of the number and the size of the particles. It was observed that the higher the concentration of lead, the larger the cuprite crystals were. On the contrary, a cut of the lead content aided the increase of small-sized $\mathrm{Cu}_{2} \mathrm{O}$ particles [18]. It could explain the higher concentrations of lead in the sealing wax ( $\mathrm{PbO} 28-30.4$ wt.\%) more than the orange samples ( $\mathrm{PbO} 8-22.4 \mathrm{wt} . \%)$.

It is usually accepted that antimony is used as a reducing agent in the sealing wax technology [87]; however, the moderate concentrations revealed by the chemical analyses, complicates an accurate interpretation. Antimony probably acted as nucleant agent, favouring the aggregation of cuprous ions, rather than reducing agent [87]. In Roman sealing wax, the content of antimony oxide is usually lower than $2 \mathrm{wt} . \%$, while it was higher than $4 \mathrm{wt} . \%$ in the sealing wax produced before the Roman age $[6,18,70]$. It suggests a change in the recipes, probably due to a different antimony-bearing material or because of an improvement in the heat treatment process. In the orange samples (Gr-5), antimony, iron and tin were often higher than $1 \mathrm{wt} . \%$, suggesting an intentional addition to encourage an increase of the nucleus number. The reduction of $\mathrm{Cu}^{2+}$ to $\mathrm{Cu}^{+}$was much easier than that of $\mathrm{Cu}^{+}$to $\mathrm{Cu}^{\circ}$, hence the moderate amount of reducing agent (such as $\mathrm{Fe}^{2+}, \mathrm{Sn}^{2+}, \mathrm{Sb}^{3+}$ ) might hamper the precipitation of metallic copper. However, a strong reducing agent such as metallic iron, metallic tin and carbon should be excluded, in order to avoid the formation of metallic lead, which could damage the wall of the ceramic crucible.

The procedure to produce these two colours required different heat treatments for the formation of $\mathrm{Cu}_{2} \mathrm{O}$ crystals of specific dimensions. In the sealing wax, it was important that the molten glass was laid at temperature slightly below the melting temperature (for a long period), to promote the formation of few nucleus. A second step was probably a gradual and prolonged cooling phase, in order to encourage the growth of crystal [17]. On the contrary, to produce orange glass, the molten glass 
should be maintained at a temperature lower than the sealing wax, in order to increase the number of small cuprite crystals [17].

The euhedral calcium antimonate crystals, detected in sample AR2, were not considered to be a possible opacifying agent or a voluntary addition to achieve a specific hue. It most probably formed as the glass started to cool or laid a temperature below the melting point, for a prolonged period [18]. In sealing wax red glass, no devitrification products were detected. High concentrations of lead probably obstructed the formation of devitrification products that prevented the development of cuprite [18].

The presence of sealing wax among the sectilia of Lucius Verus villa could open a new path in the definition of the correct chronology of its production. Other authors encountered sealing wax in Roman mosaic tesserae and enamels, but only until the 1st century AD [43,44]. In our case, sealing wax was abundantly present, which could suggest that during the 2nd century AD, this technology was not abandoned but was still well-known. Likely, the control of colour in the sealing wax was more difficult than in the brick red (Gr-1), which needed less time in its production. These factors would have favoured the employment of sealing wax only for high-status clients and at special request.

\section{Conclusions}

The multi-analytical approach used to investigate the copper red glass sectilia of the Gorga collection allowed the characterisation of several crucial aspects of this glass, providing precious insight, in order to clarify its production technology.

In this research, five red hues from orange to brown through to the red, were distinguished. Each hue was characterized by two main factors-chemical composition and the relationship of size-number of the copper-rich particles. Two main colouring techniques were detected that used two different colouring and opacifying agents-metallic copper and cuprite. They were never found together in the same samples. The nature of the colouring agents was strictly linked with the chemical composition, while the number and the size of the particles were the result of specific heat treatments.

Three recipes were identified within the metallic copper colouring technique, which included Gr-1, Gr-2 and Gr-3. In this technique, iron played an important role, and the manipulation of iron and copper proportion was a key factor to obtaining the three different red hues. Moderate concentration of copper and iron were used for the brick red glass (Gr-1), while by increasing their content, the colour moved towards reddish-brown hue (Gr-2). The production of a dark red (Gr-3) glass used very high quantities of iron and small amounts of copper, obtaining red-banded samples in which an extreme heterogeneity was composed of dark-green transparent and opaque-red layers.

Two different base glass composition were used. In order to better control the reducing condition inside the melt, ensuring a light-red colour, in the recipe of the brick red (Gr-1), a soda plant ash base glass was used. The final red colour of these samples was in many cases very close to the sealing wax, making it very difficult to distinguish them. Natron base glass was used in the Gr-2 and Gr-3 groups.

The authors support that the high concentrations of potassium and magnesium, and the lower sodium contents should be attributed to the use of a soda plant ashes as fluxing agent, rather than the addition of fuel ash to a natron base glass. It would imply the presence of specialised workshops that produced their own base glass, to manufacture specific coloured glass. However, it is still not possible to establish whether in the Roman age there were specific production centres that manufactured soda plant ash glass, and more analyses are necessary to shed light on this intriguing question.

The typical heterogeneity observed by the naked eye (Gr-3) and microscopically (Gr-1) in the metallic copper colouring technique, could be due to the continued stirring of the glass, which was included in their recipe. Conversely the reddish brown samples (Gr-2) were not affected by heterogeneity. Likely, they were produced through a specific heat treatment, in which a slow and prolonged cooling phase was employed in order to favour the crystal growth of metallic copper. The features and the chemical composition of the reddish-brown samples were very close to the 
Venetian aventurine. This attests that this technology that was attributed to the end of the 16th century AD Venetian glassmakers up till now, was known by Roman glassmakers.

In the cuprite technology, high concentrations of lead and copper were used. The chemical compositional differences detected in the two groups (Gr-4 and Gr-5), highlighted the extraordinary attention to the proportion of specific elements. The production of orange glass showed the incredible skill of manipulating the chemical composition and controlling the melting process, which at that time might have been challenging. An engineered chemical composition allowed an increase in the number of small cuprite crystals, while a mastered heat treatment allowed the control of the size. As a result of the control of this technique, four different orange hues were produced.

Sealing wax red glass seemed to present a different chemical composition compared to those produced before the Roman age. It was likely that a change in the raw material or an improvement in the heat treatment occurred. However, sealing wax red glass is an expected guest in glass from the 2nd century AD, since it is generally accepted that its production stopped around the 1st century AD. On the contrary, the abundant sectilia of sealing wax could suggest that its production was not been replaced by the red-brown but continued to be used exclusively for specific demands.

This paper enriches the corpus of analytical data of the 2nd century AD. Furthermore, due to the lack of any written source concerning recipes for colouring techniques, our results offer a reference and helpful clues to shed light on the manufacturing of opaque red glass during the 2nd century AD.

Author Contributions: Conceptualization M.B. and M.V. (Marco Verità); Data curation, M.B., P.L., M.V. (Marco Verità); Formal analysis, M.B., P.L., M.V. (Marco Verità); Investigation, M.B., P.L. and M.V. (Marco Verità); Methodology, M.B., P.L. and M.V. (Marco Verità); Supervision, M.V. (Marco Verità) and M.V. (Marcia Vilarigues); Writing—original draft, M.B.; Writing—review \& editing, M.V. (Marco Verità), P.L. and M.V. (Marcia Vilarigues). All authors have read and agreed to the published version of the manuscript.

Funding: This research was funded by the Portuguese Foundation for Science and Technology (FCT-MCTES), for PhD grant PD/BD/135053/2017.

Acknowledgments: The authors acknowledge the Portuguese Foundation for Science and Technology (FCT-MCTES) for PhD grant PD/BD/135053/2017, the Research Units VICARTE (UIDB/00729/2020) for supporting this project. A special acknowledgment to L. Saguì and Soprintendenza Archeologica di Roma, which gave us access to the glass samples studied, and Isabel Biron for the opportunity to use the Louvre laboratories for the FEG-SEM analyses; Daneo (Stazione Sperimentale del Vetro, Murano) for the colorimetric measurements; M. Bacci for his personal suggestions on the interpretation of FORS spectra; Joana Pinto of CENIMAT for the XRD measurements are kindly acknowledged.

Conflicts of Interest: The authors declare no conflict of interest.

\section{References}

1. Bamford, C.R. Colour Generation and Control in Glass; Elsevier Scientific Publishing Company: Amsterdam, The Netherlands, 1977; Volume 3, ISBN 1520-6378.

2. Weyl, W.A. Coloured Glasses; Society of Glass Technology: Sheffield, UK, 1951; ISBN 9780900682063.

3. Hofmeister, A.M.; Rossman, G.R. Exsolution of metallic copper from Lake County labradorite. Geology 1985, 139, 644-647. [CrossRef]

4. Xu, H.; Hill, T.R.; Konishi, H.; Farfan, G. Protoenstatite: A new mineral in Oregon sunstones with "watermelon" colors. Am. Mineral. 2017, 102, 2146-2149.

5. Turner, W.E.S. Glass Fragments from Nimrud of the Eighth to the Sixth Century BC. Iraq 1955, 17, 57-68. [CrossRef]

6. Brill, R.H.; Cahill, N.D. A Red Opaque Glass from Sardis and Some Thoughts on Red Opaque in General. J. Glass Stud. 1988, 30, 16-27.

7. Ishida, S.; Takeuchi, N.; Hayashi, M.; Wakamatsu, M. Role of $\mathrm{Sn}^{2+}$ in development of red colour during reheating of copper glass. J. Non Cryst. Solids 1987, 95, 793-800. [CrossRef]

8. Wakamatsu, M.; Takeuchi, N.; Nagai, H.; Ishida, S. Chemical states of copper and tin in copper glazes fired under various atmospheres. J. Am. Ceram. Soc. 1989, 72, 16-19. [CrossRef]

9. Nakai, I.; Numako, C.; Hosono, H.; Yamasaki, K. Origin of the red colour of Satsuma copper-ruby glass as determined by EXAFS and optical absorption Spectroscopy. J. Am. Ceram. Soc. 1999, 82, 689-784. [CrossRef] 
10. Padovani, S.; Sada, C.; Mazzoldi, P.; Brunetti, B.; Borgia, I.; Sgamellotti, A.; Giulivi, A.; D'Acapito, F.; Battaglin, G. Copper in glazes of Renaissance luster pottery: Nanoparticles, ions, and local environment. Appl. Phys. 2003, 93, 10058-10063. [CrossRef]

11. Tress, H.J. Ruby glass and related glasses from standpoint of the chemical potential of oxygen in glass. Part 1. Physics and Chemistry of Glasses. Glass Technol. 1962, 3, 28-36.

12. Brun, N.; Mazerolles, L.; Pernot, M. Microstructure of opaque red glass containing copper. J. Mater. Sci. Lett. 1991, 10, 1418-1420.

13. Freestone, I.C.; Stapleton, C.P.; Rigby, V. The production of red glass and enamel in the Late Iron Age. Roman and Byzantine periods. In Through a Glass Brightly: Studies in Byzantine and Medieval Art and Archaeology; Presented to David, Buckton; Entwistle, C., Buckton, D., Eds.; Oxbow Books: Oxford, UK, 2003; pp. 142-154. ISBN 978-1785702518.

14. Silvestri, A.; Tonietto, S.; D'Acapito, F.; Molin, G. The role of copper on colour of palaeo-Christian glass mosaic tesserae: An XAS study. J. Cult. Herit. 2012, 13, 137-144.

15. Silvestri, A.; Tonietto, S.; Molin, G.; Guerriero, P. The palaeo-Christian glass mosaic of St. Prosdocimus (Padova, Italy): Archaeometric characterisation of tesserae with copper- or tin-based opacifiers. J. Archaeol. Sci. 2014, 42, 51-67.

16. Ahmed, A.A.; Ashour, G.M.; El-Shamy, T.M. The effect of melting conditions on the crystallization of cuprous oxide and copper in glass. In Proceedings of the 11th international Congress of Glass, Prague, Czech Republic, 4-8 July 1977; pp. 177-187.

17. Ahmed, A.A.; Ashour, G.M. Effect of heat treatment on the crystallisation of cuprous oxide in glass. Glass Technol. 1981, 22, 24-33.

18. Freestone, I.C. Composition and microstructure of opaque red glass. In Bismon and Freestone. In Early Vitreous Materials;British Museum Occasional Paper, 56; Bimson, M., Freestone, I.C., Eds.; British Museum: London, UK, 1987; pp. 173-191. ISBN 978-0861590568.

19. Barber, D.J.; Freestone, I.C.; Moulding, K.M. Ancient copper red glasses: Investigation and analysis by microbeam techniques. In From Mine to Microscope. Advances in the Study of Ancient Technology; Shortland, A.J., Freestone, I.C., Rehren, T., Eds.; Oxbow Books: Oxford, UK, 2009; pp. 115-127; ISBN 978-1-84217-259-9.

20. Blomme, A.; Degryse, P.; Dotsika, E.; Ignatiadou, D.; Longinelli, A.; Silvestri, A. Provenance of polychrome and colourless 8the4th century BC glass from Pieria, Greece: A chemical and isotopic approach. J. Archeol. Sci. 2017, 78, 134-146.

21. Boschetti, C.; Henderson, J.; Evans, J. Mosaic tesserae from Italy and the production of Mediterranean coloured glass (4th century BCE-4th century CE). Part II: Isotopic provenance. J. Archaeol. Sci. Rep. 2017, 11, 647-657.

22. Stapleton, C.P.; Freestone, I.C.; Bowman, S.G.E. Composition and Origin of Early Mediaeval Opaque Red Enamel from Britain and Ireland. J. Archaeol. Sci. 1999, 26, 913-921.

23. Bimson, M. Opaque red glass: A review. In Early Vitreous Materials; British Museum Occasional Paper, 56; Bimson, M., Freestone, I.C., Eds.; British Museum: London, UK, 1987; pp. 165-171; ISBN 978-0861590568.

24. Hughes, M.J. A technology study of opaque red glass of the Iron Age in Britain. Proc. Prehist. Soc. 1972, 38, 98-107.

25. Brun, N.; Pernot, M. The Opaque Red Glass of Celtic Enamels from Continental Europe. Archaeometry 1992, 34, 235-252.

26. Ignatiadou, D. A Haematinon bowl from Pydna. In Proceedings of the Annales du 18e Congrès de l'Association International pour l'Histoire du Verre, Thessaloniki, Greece, 20-25 September 2009; Ignatiadou, D., Antonaras, A., Eds.; ZITI Publishing: Thessaloniki, Greece, 2012; pp. 69-74.

27. Boschetti, C. Working glass in Ptolemaic Egypt, a new evidence from Denderah. J. Archae. Sci. Rep. 2018, 22, 550-558.

28. Weinberg, G.D. Glass Vessels in Ancient Greece. Their History Illustrated from the Collection of the National Archaeological Museum, Athens; Archaeological Receipt Fund: Athens, Greek, 1992; pp. 112-115.

29. Bandiera, M.; Lehuédé, P.; Verità, M.; Alves, L.; Biron, I.; Vilarigues, M. Nanotechnology in Roman Opaque Red Glass from the 2nd Century AD. Archaeometric Investigation in Red Sectilia from the Decoration of the Lucius Verus Villa in Rome. Heritage 2019, 2, 2597-2611.

30. Arletti, R. Roman coloured and opaque glass: A chemical and spectroscopic study. Appl. Phys. A 2006, 83, 239-245. 
31. Moretti, C.; Gratuze, B. Vetri rossi al rame e avventurina. Confronto di analisi e ricette. Riv. Stn. Sper. Vetro 1999, 3, 147-160.

32. Sayre, E.V.; Smith, R.W. Compositional categories of ancient glass. Science 1961, 133, 1824-1826.

33. Freestone, I.C.; Gorin-Rose, Y.; Hughes, M.J. Primary glass from Israel and the production of glass in Late antiquity and the early Islamic period. In La Route du Verre, Ateliers Primaires et Secondaries du Second Millenaire av. J.-C. ou Moyen Age (TMO 33); Nenna, M.D., Ed.; Maison d'Orient: Lyon, France, 2000; pp. 65-83.

34. Paynter, S.; Kearns, T.; Cool, H.; Chenery, S. Roman coloured glass in the Western provinces: The glass cakes and tesserae fromWest Clacton in England. J. Archaeol. Sci. 2015, 62, 66-81.

35. Jackson, C.M.; Cottam, S. 'A green though in a green shade'; Compositional and typological observation concerning the production of emerald green glass vessels in the 1st century AD. J. Archaeol. Sci. 2015, 61, 139-148.

36. Freestone, I.; Stapleton, P.C. Composition, technology and production of coloured glasses from mosaic vessels of the early Roman Empire. In Glass of the Roman Empire; Bayley, J., Freestone, I., Jackson, C., Eds.; Oxbow: Oxford, UK, 2013.

37. Schibille, N.; Degryse, P.; Corremans, M.; Specht, C.G. Chemical characterisation of glass mosaic tesserae from sixth-century Sagalassos (south-west Turkey): Chronology and production techniques. J. Archaeol. Sci. 2012, 39, 1480-1492. [CrossRef]

38. Fiori, C. Production technology of Byzantine red mosaic glasses. Ceram. Int. 2015, 41, 3152-3157.

39. Maltoni, S.; Silvestri, A.; Molin, G. Opaque red glass tesserae from Roman and early-Byzantine sites of north-eastern Italy: New light on production technologies. In Proceedings of the Annales du 20e Congrès de l'Association Internationale pour l'Histoire du Verre, Fribourg, Switzerland, 7-11 September 2015; Wolf, S., de Pury-Gysel, A., Eds.; Verlag Marie Leidorf GmbH: Rahden, Germany, 2017; pp. 280-287.

40. Maltoni, S.; Silvestri, A. A Mosaic of Colors: Investigating Production Technologies of Roman Glass Tesserae from North eastern Italy. Minerals 2018, 8, 255.

41. Verità, M.; Santopadre, P. Unusual Glass Tesserae from a Third-century Mosaic in Rome. J. Glass. Stud. 2015, 57, 287-292.

42. Nenna, M.D.; Gratuze, B. Etude diachronique des compositions de verres employes dans les vases mosaiques antiques: Resultats preliminaires. In Proceedings of the Annales du 17e Congrés de l'Association Internationale pour 1'Histoire du Verre, Antwerp, Belgium, 4-8 September 2006; Janssens, K., Degryse, P., Cosyns, P., Caen, J., Van't dack, L., Eds.; University Press Antwerp: Antwerp, Belgium, 2009; pp. 199-205.

43. Boschetti, C.; Henderson, J.; Evans, J.; Leonelli, C. Mosaic tesserae from Italy and the production of Mediterranean coloured glass (4th century BCE-4th century CE). Part I: Chemical composition and technology. J. Archaeol. Sci. Rep. 2016, 7, 303-311.

44. Henderson, J. Chemical characterization of Roman glass vessels, enamels and tesserae. Jezvel. Stud. 1991, 5, 65-77. [CrossRef]

45. Santagostino Barbone, A.; Gliozzo, E.; D’acapito, F.; Memmi Turbanti, I.; Turchiano, M.; Volpe, G. The sectilia panels of faragola (Ascoli Satriano, southern Italy): A multi-analytical study of the red, orange and yellow glass slabs. Archaeometry 2008, 50, 451-473. [CrossRef]

46. Barca, D.; Basso, E.; Bersani, D.; Galli, G.; Invernizzi, C.; La Russa, M.F.; Lottici, P.P.; Malagodi, M.; Ruffolo, S.A. Vitreous tesserae from the calidarium mosaics of the Villa dei Quintili, Rome. Chemical composition and production technology. Microchem. J. 2016, 124, 726-735. [CrossRef]

47. Schibille, N.; Boschetti, C.; Valero, M.A.; Veron, E.; Juan, J. The Color Palette of the Mosaics in the Roman Villa of Noheda (Spain). Minerals 2020, 10, 272. [CrossRef]

48. Davidson, S. Conservation and Restoration of Glass, 2nd ed.; Butterworth-Heinemann Publisher: Oxford, UK, 1997.

49. Brill, R.H. Kenchreai Panel Revisited; The Corning Glass Newsletter, Summer: Corning, NY, USA, 1996; pp. 1-2.

50. Saguì, L.; Santopadre, P.; Verità, M. Technology. Colours, Forms, and Shapes in the 2nd Century Glass Opus Sectile Materials from the Villa of Lucius Verus in Rome. In Proceedings of the Annales du 18e Congrès de l'Association International pour l'Histoire du Verre, Thessaloniki, Greece, 20-25 September 2009; Ignatiadou, D., Antonaras, A., Eds.; ZITI Publishing: Thessaloniki, Greece, 2012; pp. 133-138. 
51. Bacchelli, B.; Barbera, M.; Pasqualucci, R.; Saguì, L. Nuove scoperte sulla provenienza dei pannelli in opus sectile vitreo della Collezione Gorga. In Proceedings of the Conference: Atti del II Colloquio AISCOM, Roma, Italy, 5-7 December 1994; Bragantini, I., Guidobaldi, F., Eds.; Istituto Internazionale di Studi Liguri: Bordighera, Italy, 1995; pp. 447-466.

52. Caserta, E. Roma (via Cassia) —La villa di Lucio Vero alla luce delle recenti indagini archeologiche. In Notizie degli scavi di Antichità; Bardi Edizioni: Roma, Italy, 2012; pp. 53-191.

53. Verità, M.; Maggetti, M.; Saguì, L.; Santopadre, P. Colors of Roman Glass: An Investigation of the Yellow Sectilia in the Gorga Collection. J. Glass Stud. 2013, 55, 21-34.

54. Tesser, E.; Verità, M.; Lazzarini, L.; Falcone, R.; Saguì, L.; Antonelli, F. Glass in imitation of exotic marbles: An analytical investigation of 2nd century AD Roman sectilia from the Gorga collection. J. Cult. Herit. 2020, 42, 202-212. [CrossRef]

55. Rosi, F.; Grazia, C.; Gabrieli, F.; Romani, A.; Paolantoni, M.; Vivani, R.; Brunetti, B.G.; Colomban, P.; Miliani, C. $\mathrm{UV}-$ Vis-NIR and micro-Raman spectroscopies for the no destructive identification of Cd1-xZnxS solid solutions in cadmium yellow pigments. Microchem. J. 2016, 124, 856-867. [CrossRef]

56. Tauc, J.; Grigorovici, R.; Vancu, A. Optical properties and electronic structure of amorphous germanium. Phys. Status Solidi 1966, 15, 627-637. [CrossRef]

57. Murphy, A.B. Band-gap determination from diffuse reflectance measurements of semiconductor films. and application to photoelectrochemical water-splitting. Sol. Energy Mater. Sol. Cells 2007, 91, 1326-1337. [CrossRef]

58. Theja, G.S.; Lowrence, R.C.; Ravi, V.; Nagarajan, S.; Anthony, S.P. Synthesis of $\mathrm{Cu}_{2} \mathrm{O}$ micro/nanocrystals with tunable morphologies using coordinating ligands as structure controlling agents and antimicrobial studies. CrystEngComm 2014, 16, 9866-9872. [CrossRef]

59. Verità, M.; Basso, R.; Wypyski, M.T.; Koestler, R.J. X-ray microanalysis of ancient glassy materials: A comparative study of wavelength dispersive and energy dispersive technique. Archaeometry 1994, 36, 241-251.

60. Aceto, M.; Agostino, A.; Fenogli, G.; Idone, A.; Gulmini, M.; Picollo, M.; Ricciardi, P.; Delaney, J.K. Characterisation of colourants on illuminated manuscripts by portable fibre optic UV-visible-NIR. reflectance spectrophotometry. Anal. Method 2014, 6, 1488-1500.

61. Picollo, M.; Aceto, M.; Vittorino, T. UV-Vis spectroscopy. Phys. Sci. Rev. 2018, 4, 1-14.

62. Bacci, M.; Corallini, A.; Orlando, A.; Picollo, M.; Radicati, B. The ancient stained windows by Nicolò di Pietro Gerini in Florence. A novel diagnostic tool for non-invasive in situ diagnosis. J. Cult. Herit. 2007, 8, $235-241$.

63. Drünert, F.; Blanz, M.; Pollok, K.; Pan, Z.; Wondraczek, L.; Möncke, D. Copper-based opaque red glasses e Understanding the colouring. Opt. Mater. 2018, 76, 375-381.

64. Nagao, H.; Misonou, M.; Kawahara, H. Mechanism of Coloration in Copper-Stained Float Glass. J. Non Cryst. Solids 1990, 120, 199-206.

65. Capatina, C. The study of copper ruby glass. Ceram. Silik. 2005, 49, 283-286.

66. Möncke, D.; Palles, D.; Palamara, E.; Papageorgiou, M.; Kamitsos, E.I.; Zacharias, N. Coloring Vitreous Materials: Pigments. Colloids and Ions in Glasses and Glazes from the Mycenaean to Medieval Periods-Probed by Spectroscopic Techniques. In Proceedings of the Conference: 3rd ARCH_RNT Archaeological Research and New Technologies, Kalamata, Greece, 22-23 October 2010; pp. 153-164.

67. Bacci, M.; Baldini, F.; Carla, R.; Linari, R. Color Analysis of the Brancacci Chapel Frescoes. Appl. Spectrosc. 1991, 45, 26-31.

68. Banerjee, S.; Chakravorty, D. Optical absorption by nanoparticles of $\mathrm{Cu}_{2} \mathrm{O}$. Europhys. Lett. 2000, 52, 468-473.

69. Vratny, F.; Kokalas, J.J. The Reflectance Spectra of Metallic Oxides in the 300 to 1000 Millimicron Region. Appl. Spectrosc. 1962, 16, 176-184.

70. Brill, R.H. Chemical Analyses of Early Glasses; Volume 2 Tables of Analyses; The Corning Museum of Glass: Corning, NY, USA, 1999; ISBN 0-872900-143-2.

71. Lilyquist, C.; Brill, R.H. Studies in Early Egyptian Glass; Metropolitan Museum of Art: New York, NY, USA, 1993; ISBN 978-0300200195.

72. Colomban, P.; Schreiber, H.D. Raman signature modification induced by copper nanoparticles in silicate glass. J. Raman Spectrosc. 2005, 36, 884-890. [CrossRef]

73. Colomban, P.; Tourniè, A.; Ricciardi, P. Raman spectroscopy of copper nanoparticle-containing glass matrices: Ancient red stained-glass windows. J. Raman Spectrosc. 2009, 40, 1949-1955. [CrossRef] 
74. Cesaratto, A.; Sichel, P.; Bersani, D.; Lottici, P.P.; Montenero, A.; Salvioli-Mariani, E.; Catarsi, M. Characterization of archeological glasses by micro-Raman spectroscopy. J. Raman Spectrosc. 2010, 41, 1682-1687.

75. Basso, E.; Invernizzi, C.; Malagodi, M.; La Russa, M.F.; Bersani, D.; Lottici, P.P. Characterization of colorants and opacifiers in roman glass mosaic tesserae through spectroscopic and spectrometric techniques. J. Raman Spectrosc. 2014, 45, 238-245. [CrossRef]

76. Meyer, B.K.; Polity, A.; Reppin, D.; Becker, M.; Hering, P.; Kramm, B.; Klar, P.J.; Sander, T.; Reindl, C.; Heiliger, C.; et al. The physics of copper oxide $\left(\mathrm{Cu}_{2} \mathrm{O}\right)$. Semicond. Semimet. 2013, 88, 201-226.

77. Volf, M.B. Chemical Approach to Glass; Elsevier Science Publishing Company Inc.: Amsterdam, The Netherlands, 1984; Volume 7, ISBN 0-444-99635-4.

78. Gedzevičiūtē, V.; Welter, N.; Schüssler, U.; Weiss, C. Chemical composition and colouring agents of Roman mosaic and millefiori glass, studied by electron microprobe analysis and Raman microspectroscopy. Archaeol. Anthropol. Sci. 2009, 1, 15-29.

79. Tite, M.S.; Shortland, A.; Maniatis, Y.; Kavoussanaki, D.; Harris, S.A. The composition of the soda-rich and mixed alkali plant ashes used in the production of glass. J. Archaeol. Sci. 2006, 33, 1284-1292. [CrossRef]

80. Kunicki-Goldfinger, J.; Freestone, I.C.; McDonald, I.; Hobot, J.A.; Gilderdale-Scott, H.; Ayers, T. Technology, production and chronology of red window glass in the medieval period-Rediscovery of a lost technology. J. Archaeol. Sci. 2014, 41, 89-105.

81. Tress, H.J. Ruby glass and related glasses from standpoint of the chemical potential of oxygen in glass. Part 2. Gold and copper glasses. Glass Technol. 1962, 3, 95-106.

82. Ratke, L.; Vooehees, P.W. Growth and Coarsening. Ostawald Ripening, in Material Processing, 1st ed.; Springer: New York, NY, USA, 2002; ISBN 978-3-642-07644-2.

83. Moretti, C.; Gratuze, B.; Hreglich, S. L'avventurina: (II parte) la tecnologia e le analisi. Riv. Stn. Sper. Vetro 2010, 6, 29-47.

84. Cholakova, A.; Rehren, T. Producing black glass during the Roman period-notes on a crucible fragment from Serdica, Bulgaria. In Proceedings of the 39th International Symposium for Archaeometry, Leuven, Belgium, 28 May-1 June 2012; Scott, R., Braekmans, M., Degryse, P., Eds.; Centre for Archaeological Sciences: Leuven, Belgium, 2014; pp. 261-267.

85. Rehren, T.; Cholakova, A.; Zivanovi, C.M. The making of black glass in Late Roman Doclea. New Antiq. Doclea 2012, 3, 71-90.

86. Maltoni, S.; Silvestri, A. Innovation and tradition in the fourth century mosaic of the Casa delle Bestie Ferite in Aquileia, Italy: Archaeometric characterisation of the glass tesserae. Archaeol. Anthropol. Sci. 2018, 10, 415-429. [CrossRef]

87. Cable, M.; Smedley, J.W. The Replication of an opaque red glass from Nimrud. In Early Vitreous Materials; British Museum Occasional Paper 56; Bimson, M., Freestone, I.C., Eds.; British Museum: London, UK, 1987; pp. 151-164. ISBN 978-0861590568.

(C) 2020 by the authors. Licensee MDPI, Basel, Switzerland. This article is an open access article distributed under the terms and conditions of the Creative Commons Attribution (CC BY) license (http://creativecommons.org/licenses/by/4.0/). 